US Army Corps of Engineers ${ }_{\circledast}$

Engineer Research and

Development Center

\title{
Improved Ribbon Bridge Structural Response Validation Testing
}

M. Wesley Trim and Richard E. Bennett

May 2020

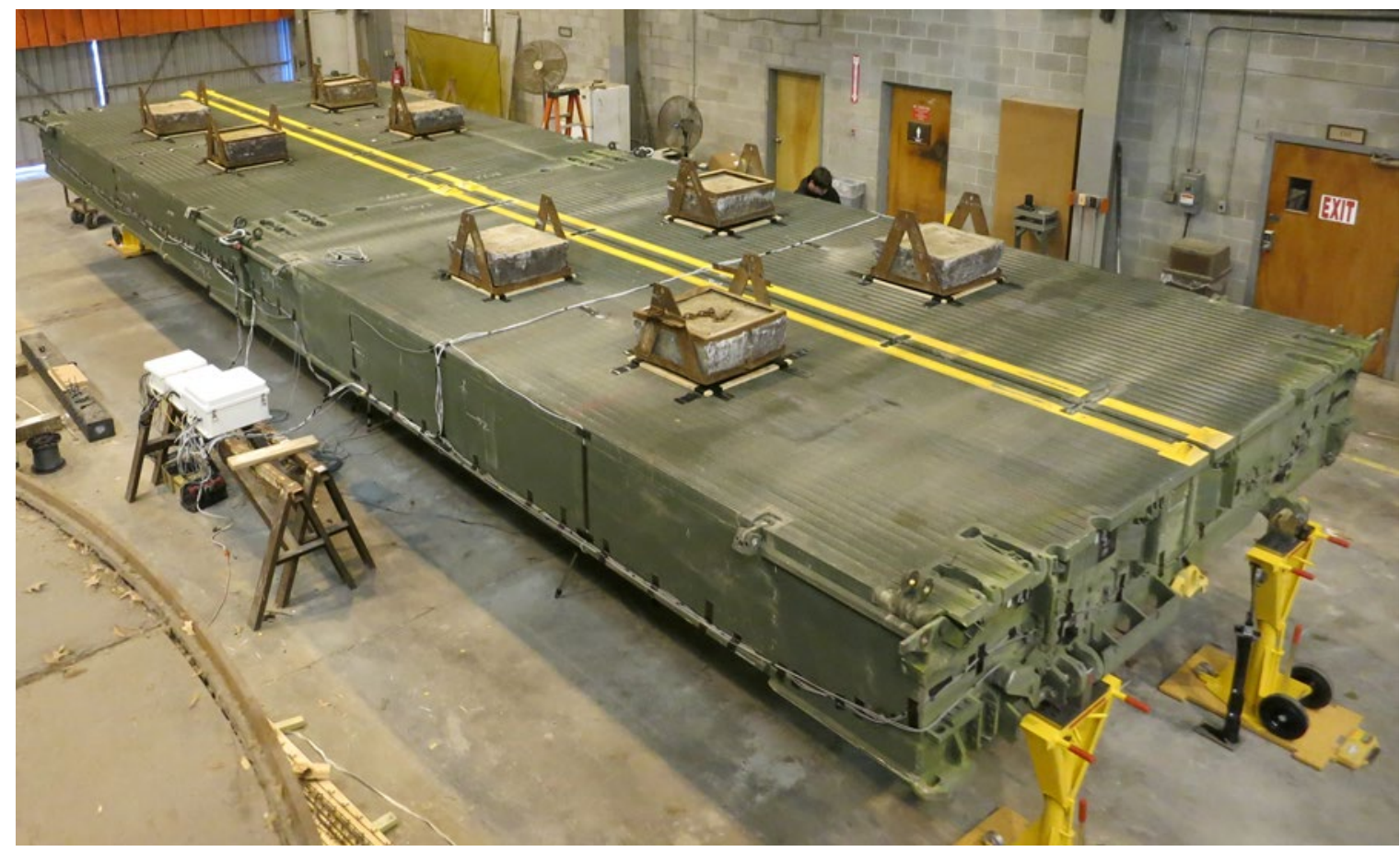


The US Army Engineer Research and Development Center (ERDC) solves the nation's toughest engineering and environmental challenges. ERDC develops innovative solutions in civil and military engineering, geospatial sciences, water resources, and environmental sciences for the Army, the Department of Defense, civilian agencies, and our nation's public good. Find out more at www.erdc.usace.army.mil.

To search for other technical reports published by ERDC, visit the ERDC online library at http://acwc.sdp.sirsi.net/client/default. 


\section{Improved Ribbon Bridge Structural Response Validation Testing}

M. Wesley Trim and Richard E. Bennett

Geotechnical and Structures Laboratory

US Army Engineer Research and Development Center

3909 Halls Ferry Road

Vicksburg, MS 39180-6199

Final report

Approved for public release; distribution is unlimited

Prepared for Assistant Product Manager/Project Officer

Office of the Product Manager, Bridging

SFAE-CSS-FP-H, Bldg 230, Mail Stop \#401

6501 East 11 Mile Road

Warren, Ml 48397-5000

Under Program Element No. 622784; Project No. 464569; Task No. 16; Funding

Account Code U4365732; AMSCO Code 622784T4000; MIPR 11326139 


\section{Abstract}

The Improved Ribbon Bridge (IRB) is a mobile, modular bridge system designed to provide wet-gap crossing capability to combat vehicles and trucks up to Military Load Capacity 96. The Bridge Supplemental Set (BSS) includes Bridge Erection Boats and an anchorage system to allow for the positioning and securing of the bridge in moving water. Designed to function as either a floating bridge or a raft, the IRB and BSS give military commanders multiple options with regards to the tactical river crossings.

The US Army Engineer Research and Development Center (ERDC) was contracted by Product Manager Bridging to provide a structural analysis via high-fidelity numerical modeling of various IRB spans and water flow rates. To this end, a finite element model (FEM) of the IRB was constructed using field measurements of IRB interior bays. To ensure accurate structural response characteristics of the FEM and to build confidence in the simulation results, a validation test series was devised to generate empirical data to correlate against. This report documents the IRB structural response validation testing conducted at ERDC in March 2018. The data contained in this report was used to validate the IRB structural FEM.

DISCLAIMER: The contents of this report are not to be used for advertising, publication, or promotional purposes. Citation of trade names does not constitute an official endorsement or approval of the use of such commercial products. All product names and trademarks cited are the property of their respective owners. The findings of this report are not to be construed as an official Department of the Army position unless so designated by other authorized documents. 


\section{Contents}

Abstract.................................................................................................................................... if

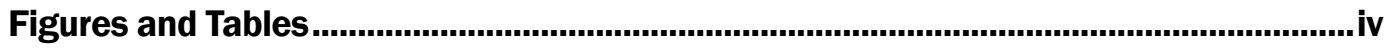

Preface

1 Introduction ........................................................................................................... 1

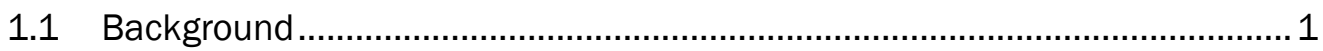

1.2 Objective .................................................................................. 1

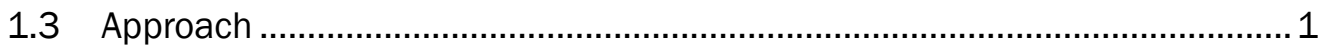

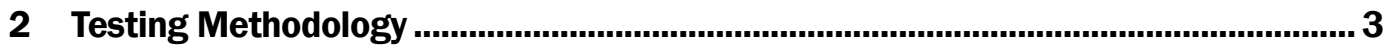

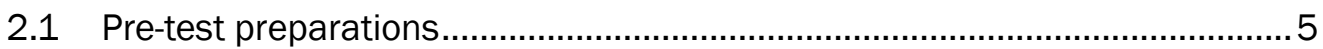

2.2 Test setup

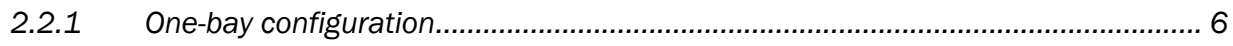

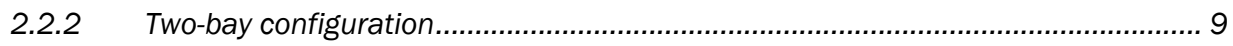

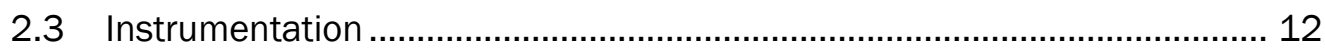

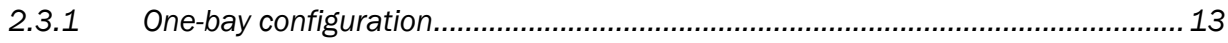

2.3.2 Two-bay configuration .............................................................................. 16

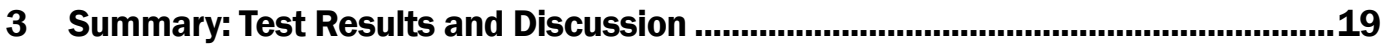

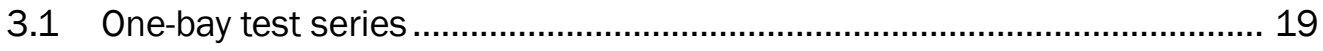

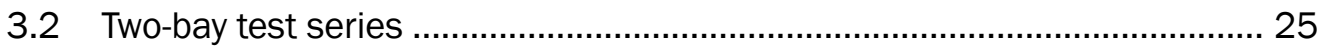

Appendix: Bay Data 2018-03-02 and 2018-03-07 ...............................................32

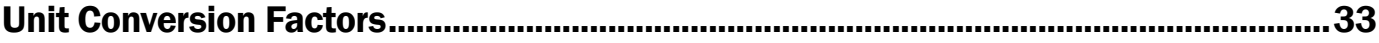

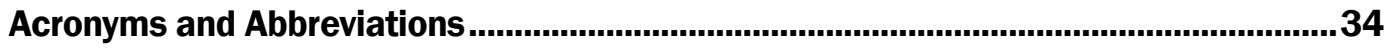

Report Documentation Page 


\section{Figures and Tables}

\section{Figures}

Figure 1. Folded IRB bay on bridge adapter pallet (BAP) ................................................... 3

Figure 2. One-bay and two-bay test configurations.......................................................... 4

Figure 3. Outer ponton separation: (a) unloading IRB bay from BAP, (b) unfolding outer pontons, (c) removing outer pontons, and (d) transporting inner pontons to test area.

Figure 4. One-bay configuration overview (a) from above, (b) from below, and (c) from end.

Figure 5. IRB structural validation test supports drawing. ................................................... 7

Figure 6. Load arrangements for one-bay tests 1-1, 1-2, and 1-3. ................................... 8

Figure 7. Representative photograph of one-bay test (test 1-2 shown). Each stack of lead blocks weighs $8,100 \mathrm{lb}_{\mathrm{f}}$.

Figure 8. Two-bay configuration overview (a) from above, (b) from below, and (c)

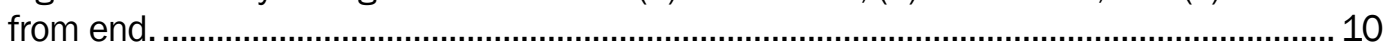

Figure 9. Load arrangements for two-bay tests 2-1, 2-2, and 2-3.................................. 11

Figure 10. Representative photograph of two-bay test (test 2-2 shown). Each lead

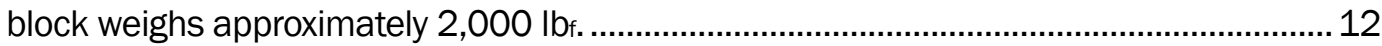

Figure 11. Weigh scale locations for one-bay configuration: (a) schematic and (b) photograph.

Figure 12. Load pin locations and orientations for one-bay configuration

Figure 13. Load pins (a) installed in single clevis (P2 shown), (b) installed in double clevis (P1 shown), and (c) side view showing axis orientations.

Figure 14. Displacement transducer locations for one-bay configuration:

(a) schematic and (b) photograph. 15

Figure 15. Strain gauge locations for one-bay configuration............................................. 15

Figure 16. Weigh scale locations for two-bay configuration............................................... 16

Figure 17. Load pin locations for two-bay configuration. .................................................. 17

Figure 18. Displacement transducer locations for two-bay configuration........................... 18

Figure 19. Strain gauge locations for two-bay configuration........................................... 18

Figure 20. Overview of one-bay tests from 2 March 2018. Illustration of testing sequence via vertical load pin and displacement data.

Figure 21. One-bay load pin and weighing scale data collected 2 March 2018............... 21

Figure 22. One-bay displacement data collected 2 March 2018...................................... 22

Figure 23. One-bay strain data collected 2 March 2018.

Figure 24. Overview of two-bay tests from 7 March 2018. Illustration of testing sequence via supported vertical load pin and vertical displacement data at mid-bridge.

Figure 25. Two-bay load pin and weighing scale data collected 7 March 2018 ............... 27

Figure 26. Two-bay displacement data collected 7 March 2018. 
Figure 27. Two-bay strain data collected 7 March 2018.

\section{Tables}

Table 1. Instrumentation package for the structural validation test series........................ 12

Table 2. IRB component weights. .... 


\section{Preface}

This study was conducted for Product Manager, Bridging, under Program Element No. 622784; Project No. 464569; Task No. 16; Funding Account Code U4365732; AMSCO Code 622784T4000; MIPR 11326139.

This work was performed by the Structural Engineering Branch (GSS) of the Geosciences and Structures Division (GSD), US Army Engineer Research and Development Center, Geotechnical and Structures Laboratory (ERDCGSL). At the time of publication of this report, Mrs. Mariely Mejias-Santiago was Chief, GSS; Mr. James L. Davis was Chief, GSD; and Mr. Nicholas Boone was the Technical Director for Force Projection and Maneuver Support. The Deputy Director of ERDC-GSL was Mr. Charles W. Ertle, II, and the Director was Mr. Bartley P. Durst.

Sincere appreciation is expressed to Mr. Tommy Carr and Mr. Tony Brogdon for their expert instrumentation and data collection assistance; to Mr. Nathan Hoben and Mr. Kenny Prince for their hard work and dedication as test technicians; and to Mr. Mickey Blackmon, Mr. Chris Ables, and the entire group of talented machinists at ERDC for their remarkable fabrication support. This work would not have been possible without the help of these gifted individuals.

COL Teresa A. Schlosser was the Commander of ERDC, and the Director was Dr. David W. Pittman. 


\section{Introduction}

\subsection{Background}

At the request of Product Manager Bridging, the US Army Engineer Research and Development Center (ERDC) is conducting research to support the modernization of the Improved Ribbon Bridge (IRB) Bridge Supplemental Set (BSS) Program of Record. ERDC has been tasked to provide an analytical study of IRB crossings at various flow rates. Areas of interest include an estimation of forces on the bridge, anchorage, and overhead cable system due to fluid drag and vehicular loading. Currently, the hydrodynamic and structural characteristics along with the limit states of the IRB are not fully understood.

In support of the analytical IRB study, a structural finite element model (FEM) of the IRB was constructed. No drawings or models of the IRB were available (the IRB is proprietary with rights belonging to General Dynamics European Land Systems), so physical measurements of several as-built IRB interior bays were taken and used to develop a computeraided drafting model, from which the FEM was built. To ensure accurate structural response characteristics of the FEM and to build confidence in the simulation results, a validation test series was devised to generate empirical data to correlate against.

\subsection{Objective}

This report documents the IRB structural response validation test series conducted at ERDC in March 2018. The objective of this study was to generate empirical data to be used to validate and calibrate (if necessary) the IRB structural FEM developed by ERDC.

\subsection{Approach}

A test series, comprising two IRB configurations was executed. In the first configuration, a single IRB bay was supported at each end, and lead weights were placed on the deck, loading the structure via gravity and producing longitudinal bending in the bridge section. The total amount of lead weight was incrementally increased from $16,200 \mathrm{lbf}$ to $32,400 \mathrm{lb}$, then to $36,560 \mathrm{lb}$. For each load case, the structural response of the IRB bay was measured using displacement transducers, load pins, weighing 
scales, and strain gauges. In the second configuration, two IRB bays were linked together, supported, and loaded in a similar fashion as in the first configuration. Three load cases were also applied to the two-bay configuration, and the structural response was measured for each. For the two-bay configuration, first 8,280 lbf was applied, then $16,360 \mathrm{lb}$, and finally 24,640 lbf. These six (three single bay and three double bay) load cases were correlated against in order to produce an accurate, validated structural FEM of the IRB. The full testing methodology is explained in chapter 2 . The test results are presented and discussed in chapter 3 . 


\section{Testing Methodology}

Each IRB bridge bay is a four-ponton, folding module consisting of two inner (roadway) pontons and two outer (bow) pontons, as shown in Figure 1. The inner pontons are joined to each other and to the adjacent bow pontons by hinges and pins along their adjacent edges. The roadway is welded to the inner pontons. Therefore, when unfolded and deployed, the two inner pontons primarily carry the vehicular loads. The two outer pontons function mainly to aid in flotation and provide walkways for personnel on both sides of the roadway. Thus, the inner pontons are the primary structural components of the bay, carrying the majority of the structural load.

Figure 1. Folded IRB bay on bridge adapter pallet (BAP).

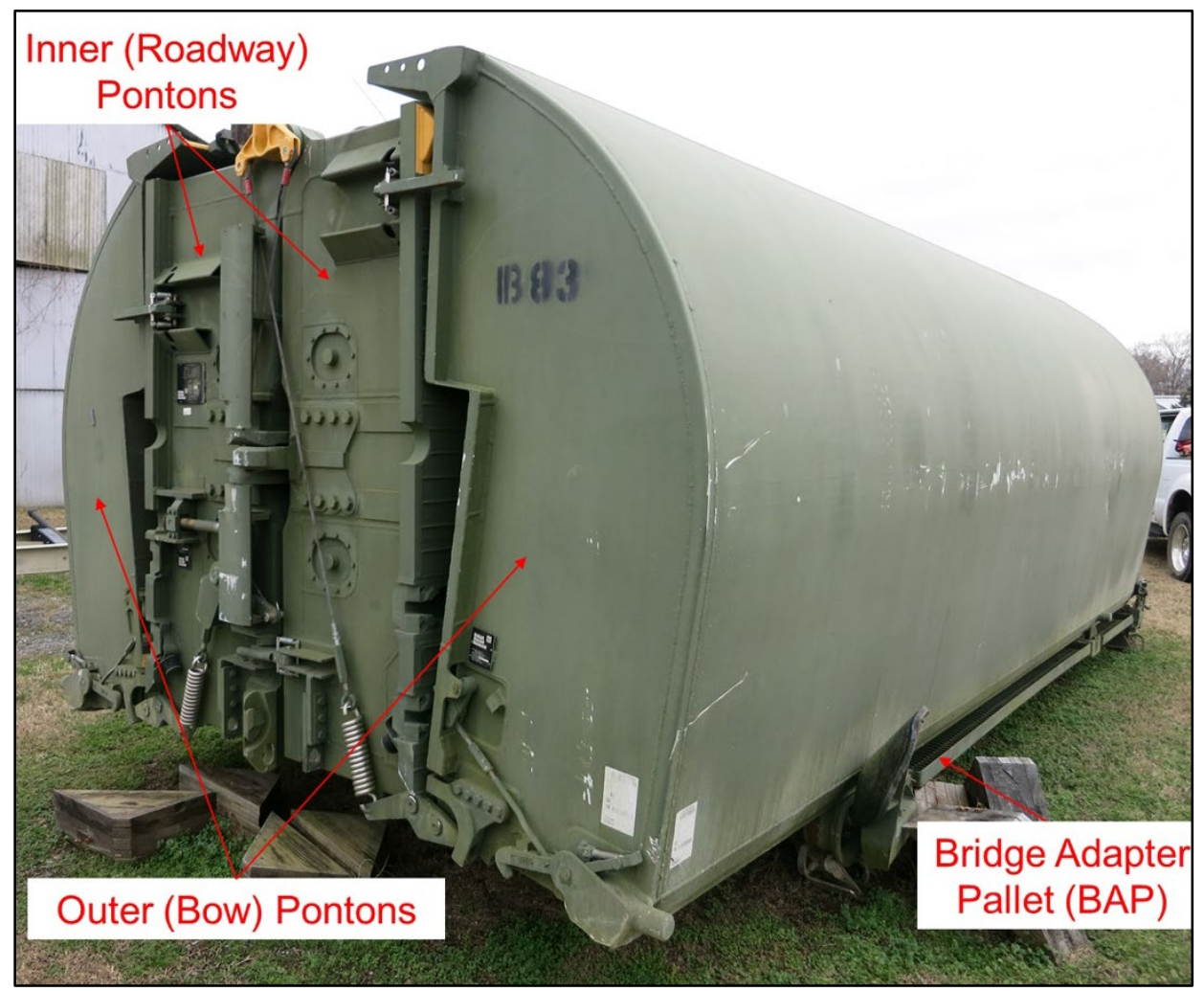

The goal of the IRB structural response validation testing was to create experimental data with well characterized load inputs, boundary conditions, and measurable, linear elastic deformation responses. The test setup and loading scheme were designed such that the experiment could be readily modeled and simulated using the finite element method for correlation purposes. 
A testing approach utilizing two configurations was devised. In the first configuration, a single IRB bay was supported at each end, and lead weights were placed on the deck, loading the structure via gravity and producing longitudinal bending in the bridge section. The single-bay tests focus on generating data that could be used to verify the stiffness and structural response of the FEM. In the second configuration, two IRB bays were linked together, supported, and loaded in a similar fashion as in the first configuration. The two-bay tests focus on generating data that could be used to verify that the interactions between the bays were modeled correctly. When loaded, the decks of the linked bays come into contact. This compressive contact is all that resists the hinged joints from rotating. Figure 2 shows a schematic of the one-bay and two-bay test configurations.

Figure 2. One-bay and two-bay test configurations.

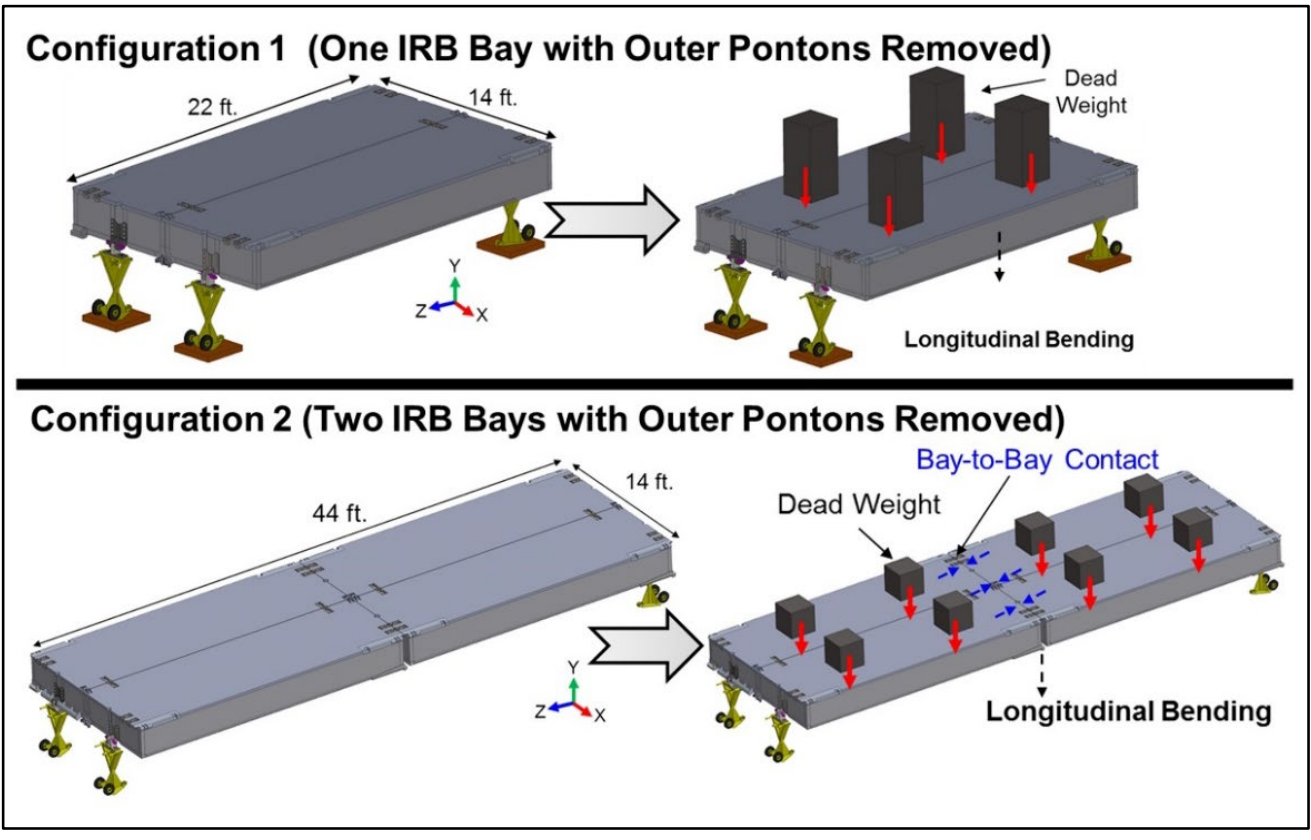

As shown in Figure 2, the outer pontons were removed for testing. The outer pontons were not included in the test setup for several reasons. As discussed above, the inner pontons are the primary load carrying members. The bulky outer pontons function only to provide additional buoyancy. Since these tests were conducted out of water, the outer pontons and their bulk would unnecessarily complicate the test setup. The omission of the outer pontons also reduced the computational expense of the computer simulated tests. For these reasons, the outer pontons were removed prior to testing. 
Section 2.1 outlines the pre-test preparations, which includes the outer ponton separation procedure. Section 2.2 gives an overview of the test setup, and Section 2.3 details the instrumentation used in the test series.

\subsection{Pre-test preparations}

Two IRB bays were required for this study and were provided to ERDC by Red River Army Depot. Each IRB bay was transported in the folded configuration on a BAP. Figure 3 shows the outer ponton separation procedure. Each bay was lifted from the BAP using a crane. The outer pontons were then unfolded and separated from the inner pontons by removing the two connecting pins on each end of the bay. The two inner pontons remained connected and were transported to the nearby test area. A dynamometer attached to the crane hook was used to measure the weight of each IRB component as it was lifted.

Figure 3. Outer ponton separation: (a) unloading IRB bay from BAP, (b) unfolding outer pontons, (c) removing outer pontons, and (d) transporting inner pontons to test area.

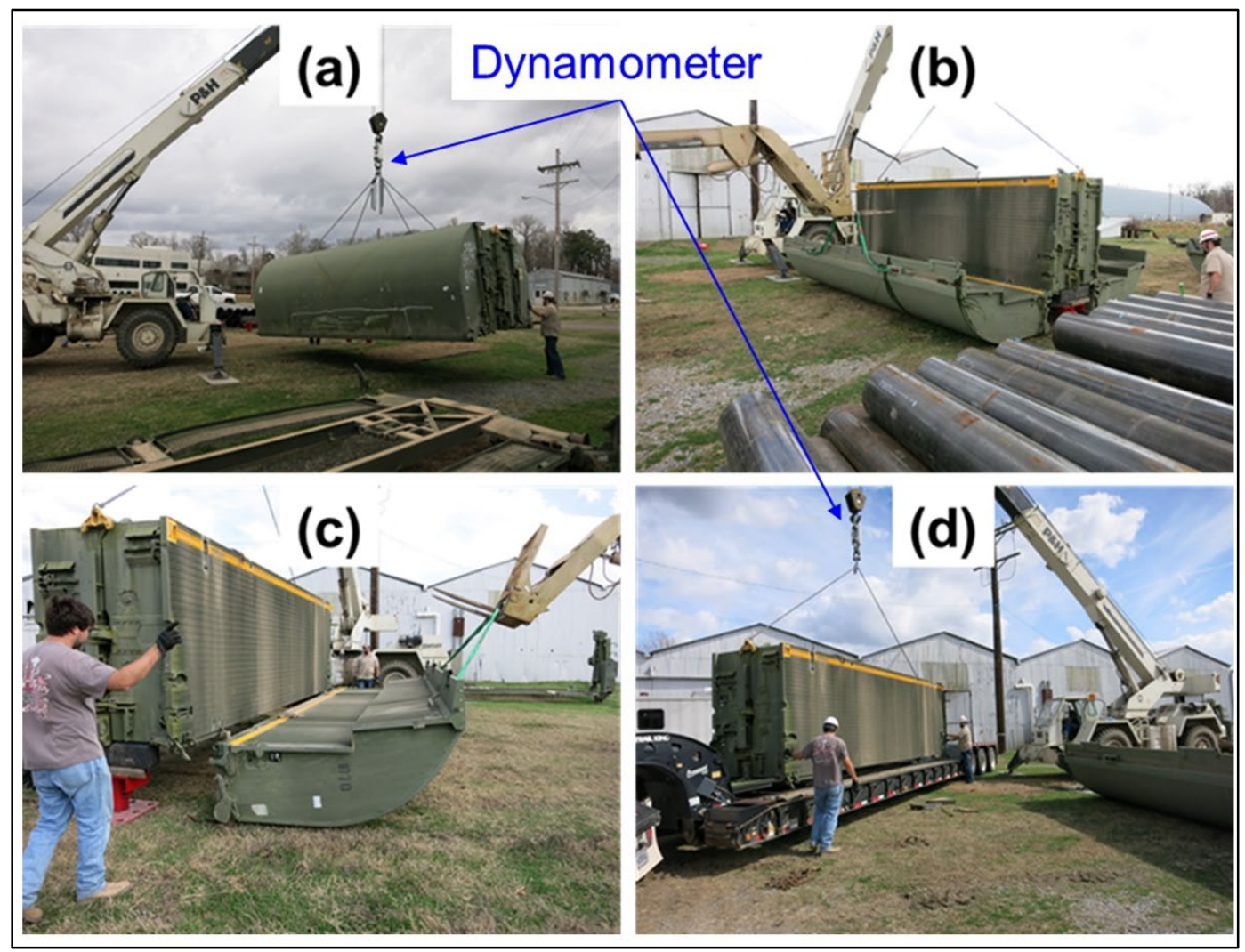




\subsection{Test setup}

Section 2.2.1 details the test setup for the one-bay configuration. The twobay test setup is covered in section 2.2.2.

\subsubsection{One-bay configuration}

Figure 4 shows an overview of the single-bay validation test configuration. The IRB bay (with outer pontons removed) was supported at the four main connection points, which are typically used to connect the bays during bridging/rafting operations, using four Vestil LO-J-BEAM stabilizing jacks. Custom pin supports were fabricated according to the drawing shown in Figure 5. The pin supports were designed to mimic a typical IRB bay-to-bay connection; each member was designed to have the same thickness and hole diameter as a corresponding IRB main coupling.

Figure 4. One-bay configuration overview (a) from above, (b) from below, and (c) from end.

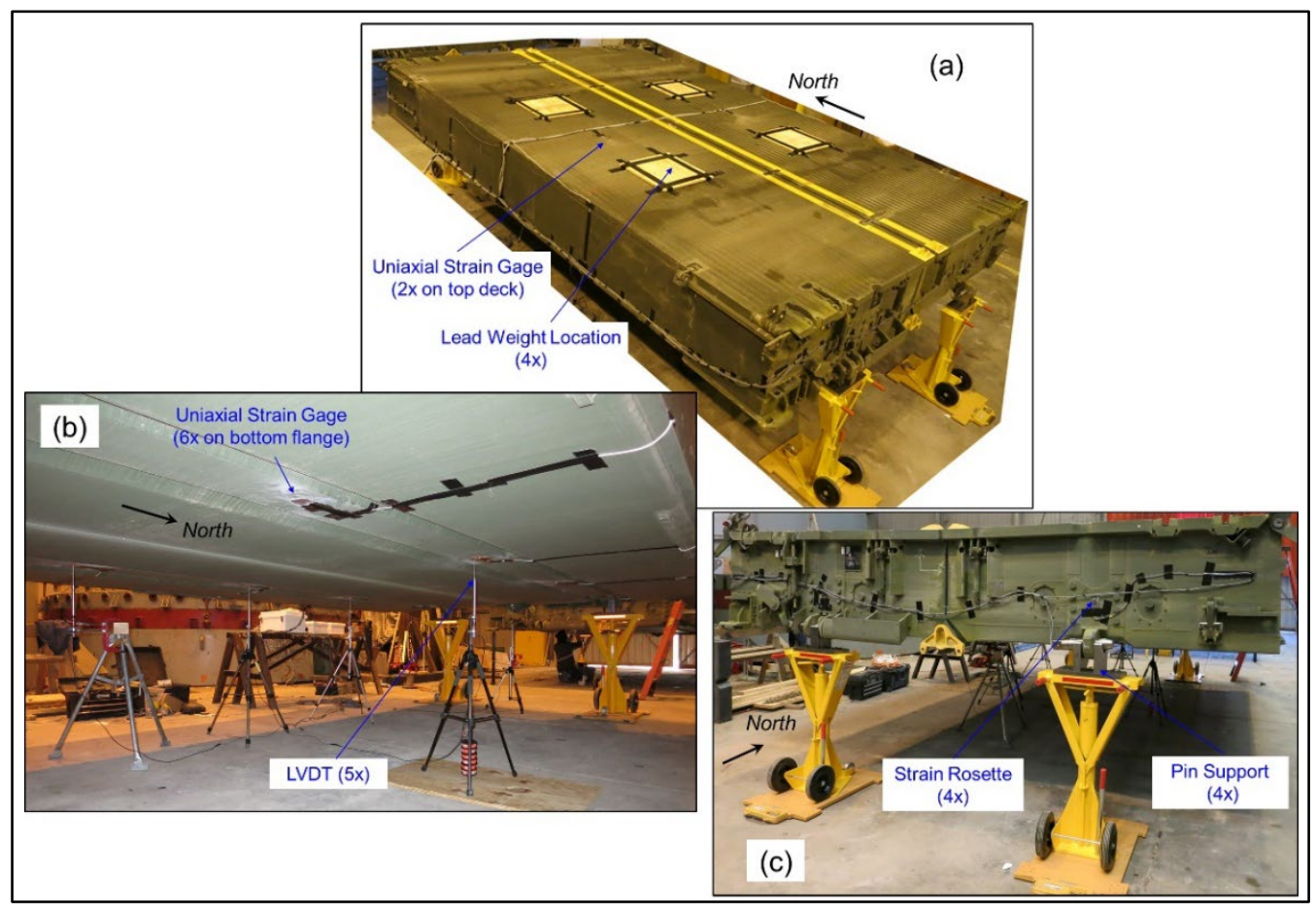


Figure 5. IRB structural validation test supports drawing.

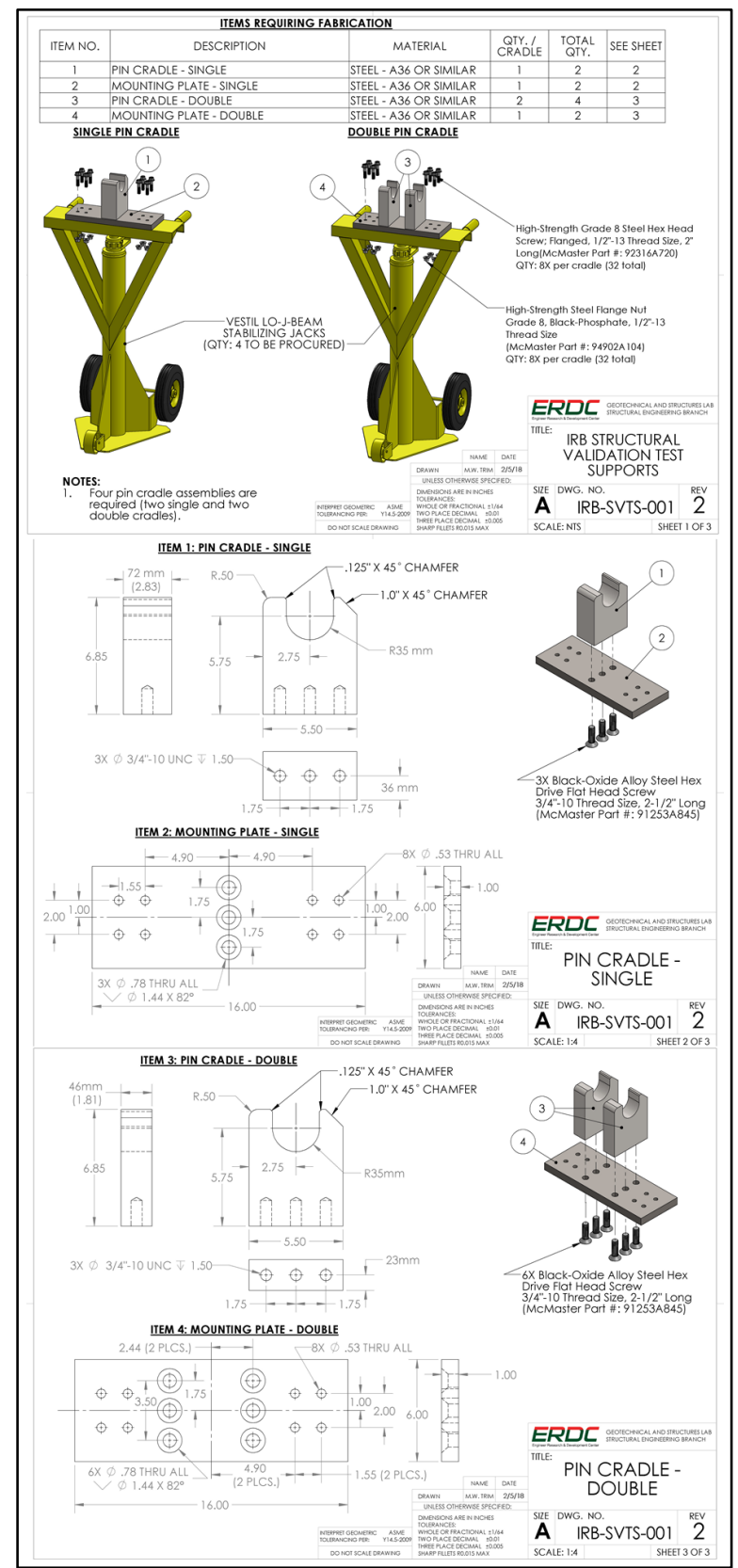

Once supported, the bay was loaded using lead weights. Three tests were conducted on the single IRB bay using lead weights of varying mass. Each lead block had a footprint of 26 in. $\times 26$ in. ${ }^{*}$ and was centered on the deck

* For a full list of the spelled-out forms of the units of measure used in this document, please refer to US Government Publishing Office Style Manual, 31st ed. (Washington, DC: US Government Publishing Office, 2016), 248-52, https://www.govinfo.gov/content/pkg/GP0-STYLEMANUAL-2016/pdf/GP0STYLEMANUAL-2016.pdf. 
quarter points of each ponton. Figure 6 shows plan views of the load arrangements for the three single-bay tests (tests 1-1, 1-2, and 1-3).

For test 1-1, four lead weights with nominal weights of $4,000 \mathrm{lb}_{\mathrm{f}}$ each were placed on the deck. For test 1-2, each weight was increased to $8,100 \mathrm{lb}_{\mathrm{f}}$ and, for test 1-3, four 9,140 lbf weight stacks were used to achieve a total load of $36,560 \mathrm{lb}$. A representative photograph of a loaded single bay is shown in Figure 7. The three single-bay tests (1-1, 1-2, and 1-3) were executed on 2 March 2018.

Figure 6. Load arrangements for one-bay tests 1-1, 1-2, and 1-3.

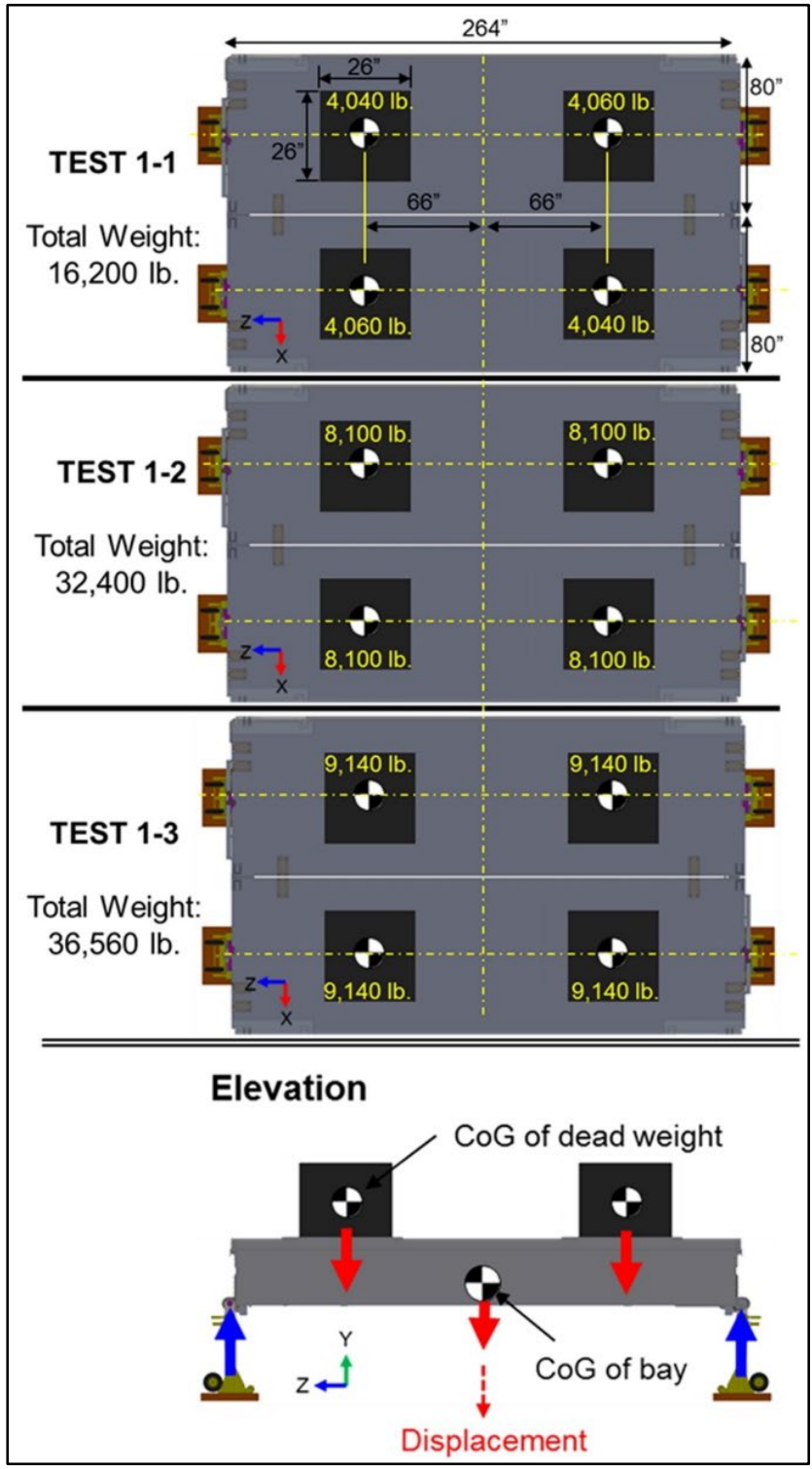


Figure 7. Representative photograph of one-bay test (test 1-2 shown). Each stack of lead blocks weighs $8,100 \mathrm{lb}_{\text {f. }}$.

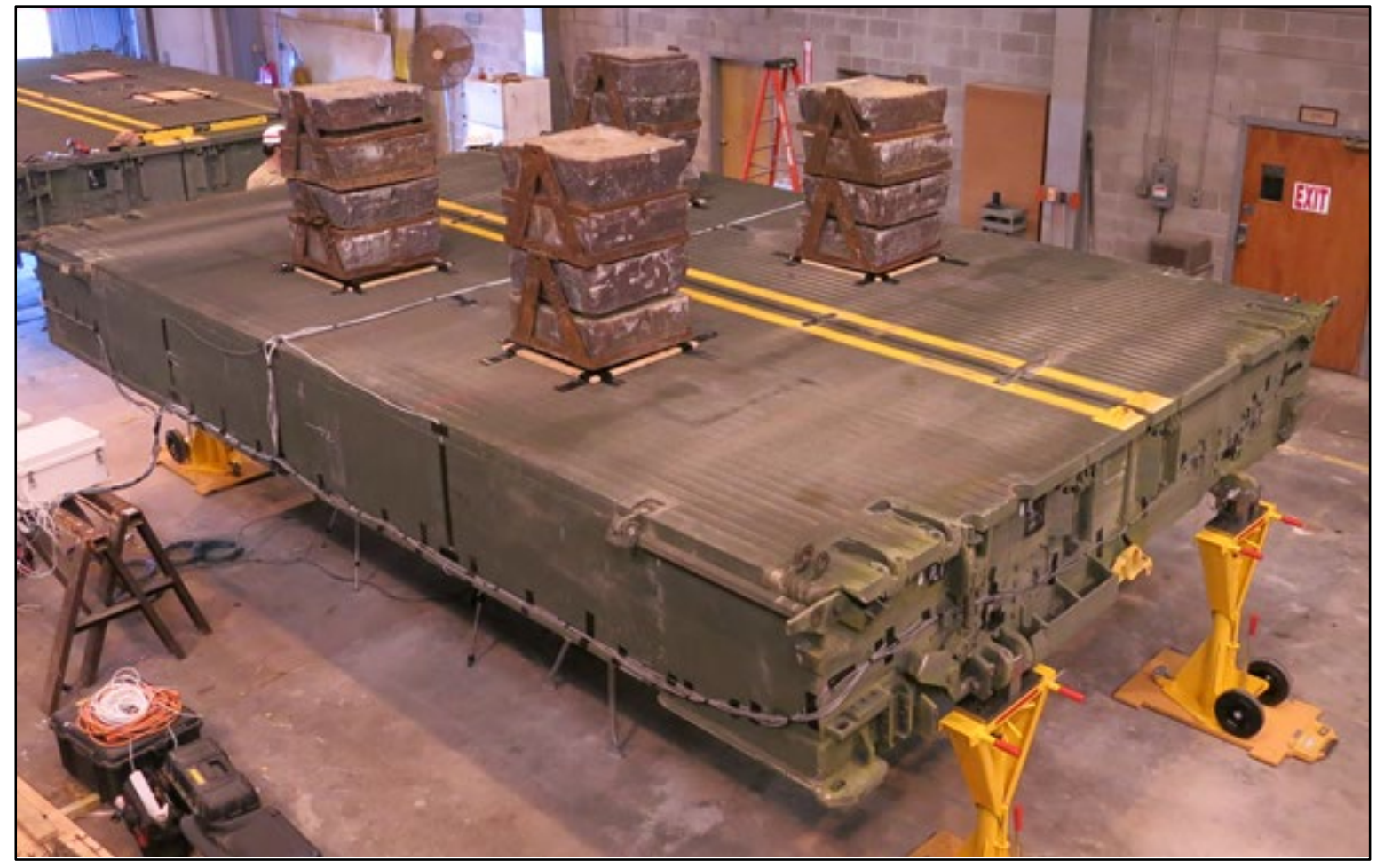

\subsubsection{Two-bay configuration}

Figure 8 shows an overview of the two-bay validation test configuration. The second bay was brought in and linked to the north end of the first bay via the two main couplings (in the same way bays are connected during bridging/rafting operations). The same pin supports used in the one-bay configuration were used for the two-bay configuration. The two pins on the south end of bay 1 and two pins on the north end of bay 2 were supported using the same Vestil stabilizing jacks. An additional stabilizing jack was used to temporarily support the center of the two bays since their self-weight caused the decks to compress together. The center jack was used to temporarily raise the center, leveling the decks of the two bays so instrumentation could be installed underneath. The center support was subsequently removed, allowing the deck compression to occur, prior to loading the bridge. 
Figure 8. Two-bay configuration overview (a) from above, (b) from below, and (c) from end.

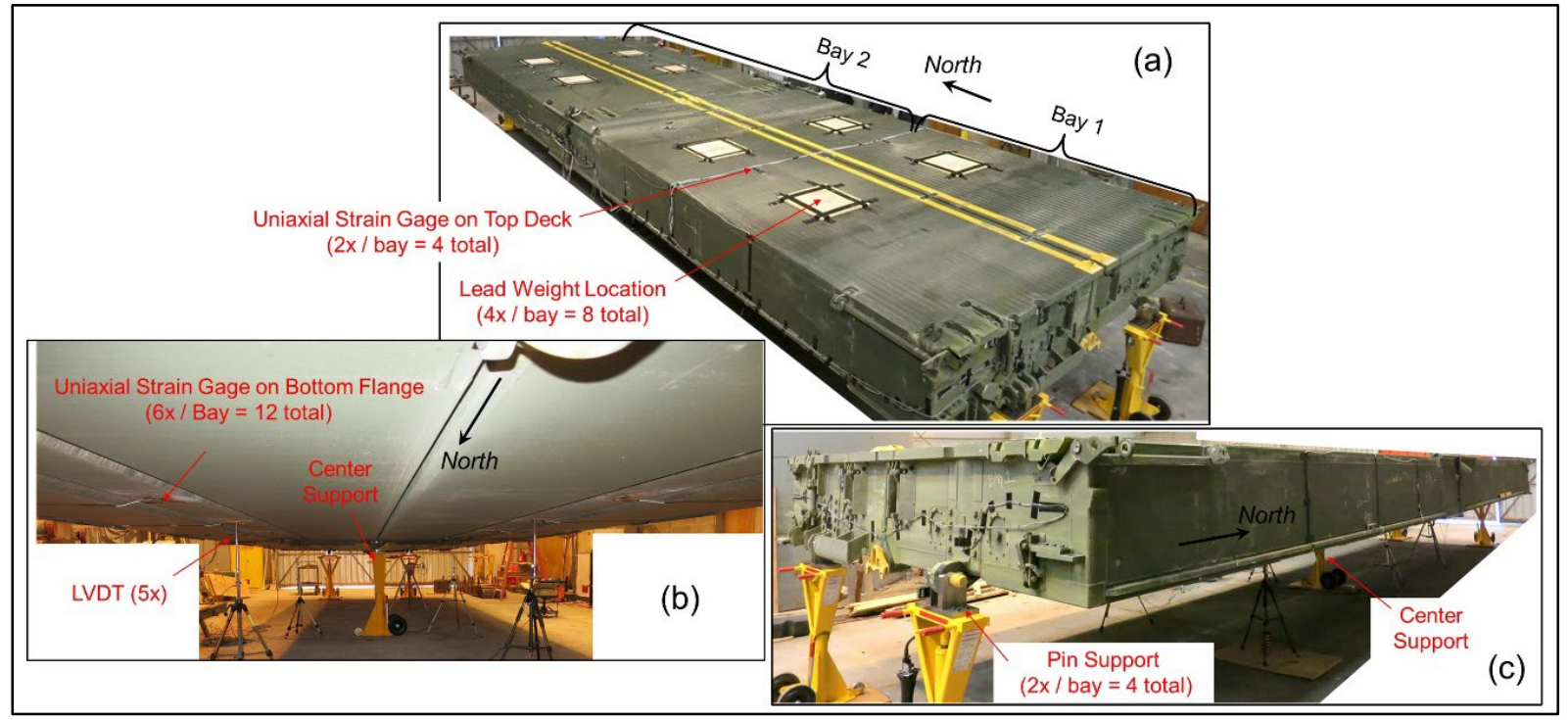

Figure 9 shows the load arrangements for the three dual-bay tests (tests 2-1, 2-2, and 2-3). Similar to the single-bay tests, three tests were conducted in the two-bay configuration using weights of varying mass. As before, each mass had a footprint of 26 in. $\times 26$ in. and was centered on the deck quarter points of each ponton.

For test 2-1, eight lead weights with nominal weights of 1,00o lbf each were placed on the bridge deck. For test 2-2, each weight was increased to approximately 2,000 lbf. For test 2-3, eight 3,080 lbf weight stacks were used to achieve a total load of $24,640 \mathrm{lb}$. A representative photograph of a two-bay loaded configuration is shown in Figure 10. All of the two-bay tests (2-1, 2-2, and 2-3) were executed on 7 March 2018. 
Figure 9. Load arrangements for two-bay tests 2-1, 2-2, and 2-3.

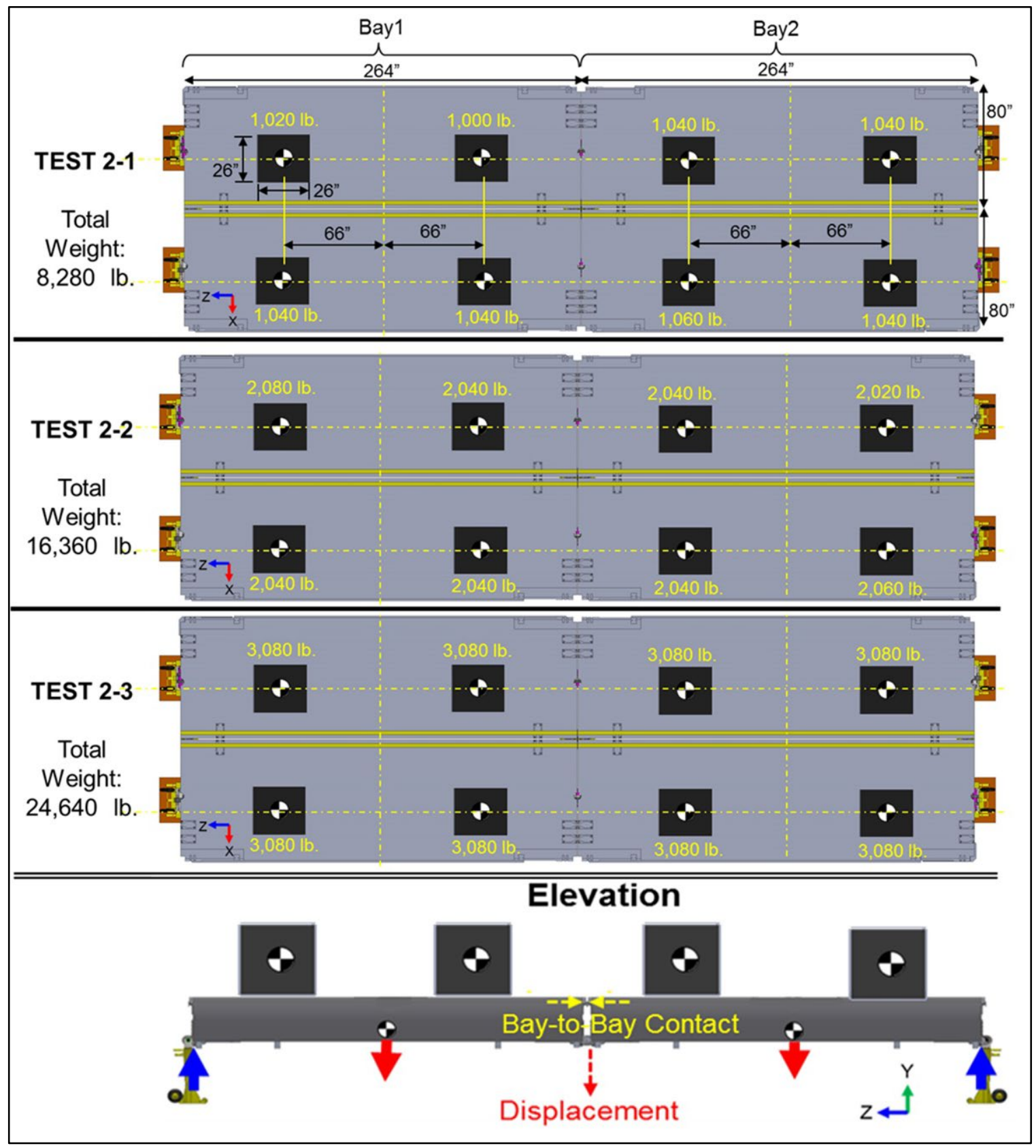


Figure 10. Representative photograph of two-bay test (test 2-2 shown). Each lead block weighs approximately $2,000 \mathrm{lb}_{\text {f. }}$.

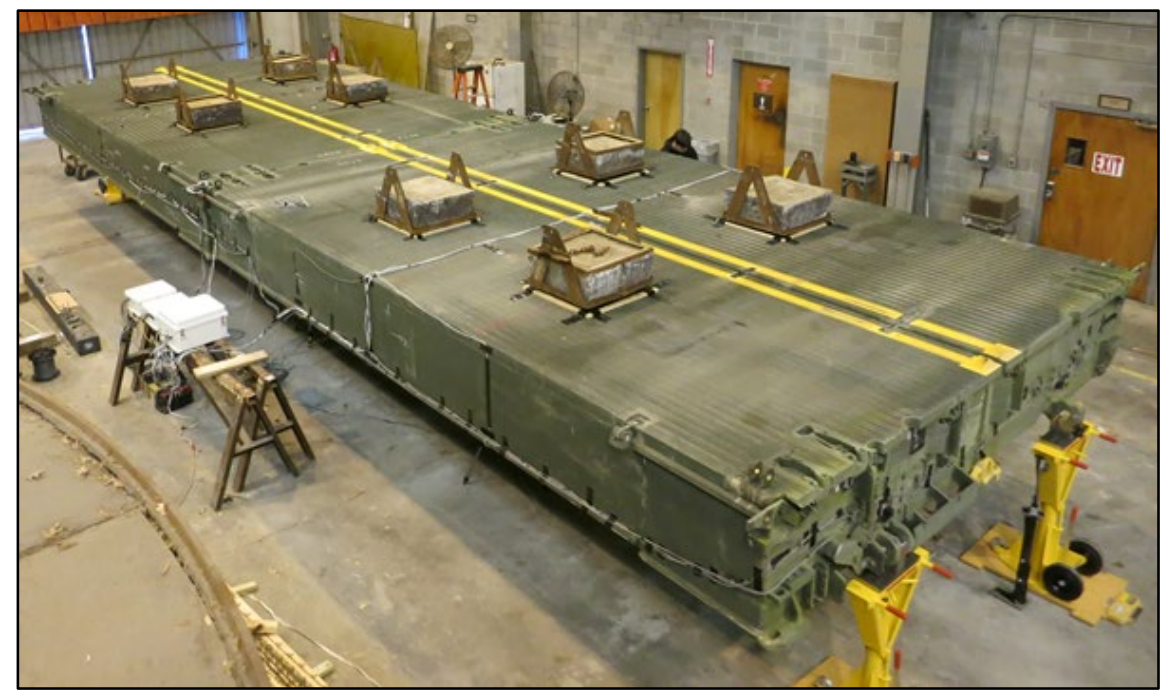

\subsection{Instrumentation}

Table 1 lists the instrumentation package for the test series. A dynamometer was used to weigh the IRB bays. Linear Variable Differential Transformers (LVDTs) were used to measure displacements during each test. Dual axis load pins measured forces on the main coupling pins in two axes (vertical and longitudinal). Vehicle weighing scales were placed under each support to measure the vertical load. Strain measurements were taken via stacked rosette and linear axial strain gauges. All gauge locations for the one-bay configuration are detailed in section 2.3.1. The gauge locations for the two-bay configuration are provided in section 2.3.2.

Table 1. Instrumentation package for the structural validation test series.

\begin{tabular}{|c|c|c|c|}
\hline Instrumentation Type & $\begin{array}{l}\text { Manufacturer and } \\
\text { Model Number }\end{array}$ & Quantity & $\begin{array}{c}\text { Accuracy } \\
\text { (\% full scale) }\end{array}$ \\
\hline Dynamometer & MSI-7300 Dyna-Link 2 & 1 & \pm 0.1 \\
\hline $\begin{array}{c}\text { Displacement Transducer } \\
\text { (LVDT) }\end{array}$ & RDP LDC2000A & 5 & \pm 0.1 \\
\hline Load Pins - Dual Axis & $\begin{array}{c}\text { StrainSert - Custom } \\
\text { Internally Gauged Force } \\
\text { Transducer }\end{array}$ & 4 & \pm 0.5 \\
\hline Vehicle Weighing Scale & CAS RWT-920F & $\begin{array}{l}\text { 1-bay: } 4 \\
\text { 2-bay: } 5\end{array}$ & \pm 0.1 \\
\hline $\begin{array}{c}\text { Stacked Rosette Strain } \\
\text { Gauge }\end{array}$ & HBM 1-RY91-6/350 & $\begin{array}{l}\text { 1-bay: } 4 \\
\text { 2-bay: } 6\end{array}$ & \pm 1.0 \\
\hline Linear Axial Strain Gauge & HBM 1-LY43-6/350 & $\begin{array}{l}\text { 1-bay: } 8 \\
\text { 2-bay: } 16\end{array}$ & \pm 1.0 \\
\hline
\end{tabular}


For all tests, the signals from the displacement transducers, load pins, and strain gauges fed into one of three Campbell Scientific CDM-A116 (16 channel) analog input modules. The input modules passed the signals to a Campbell Scientific CR6 datalogger. A custom program, written in CRBasic programming language, facilitated data collection. All data were collected at a $1 \mathrm{~Hz}$ sampling rate. A wireless radio was used to monitor and control the test from a remote position.

\subsubsection{One-bay configuration}

Figure 11 shows the weigh scale locations for one-bay configuration. A scale was placed under each support stand and zeroed under the weight of the pin support and stabilizing stand. The CAS RWT-920F scales used for the test series have a digital readout but do not have data recording capability. Therefore, the weight data from the scales were recorded manually during each test event.

Figure 11. Weigh scale locations for one-bay configuration:

(a) schematic and (b) photograph.

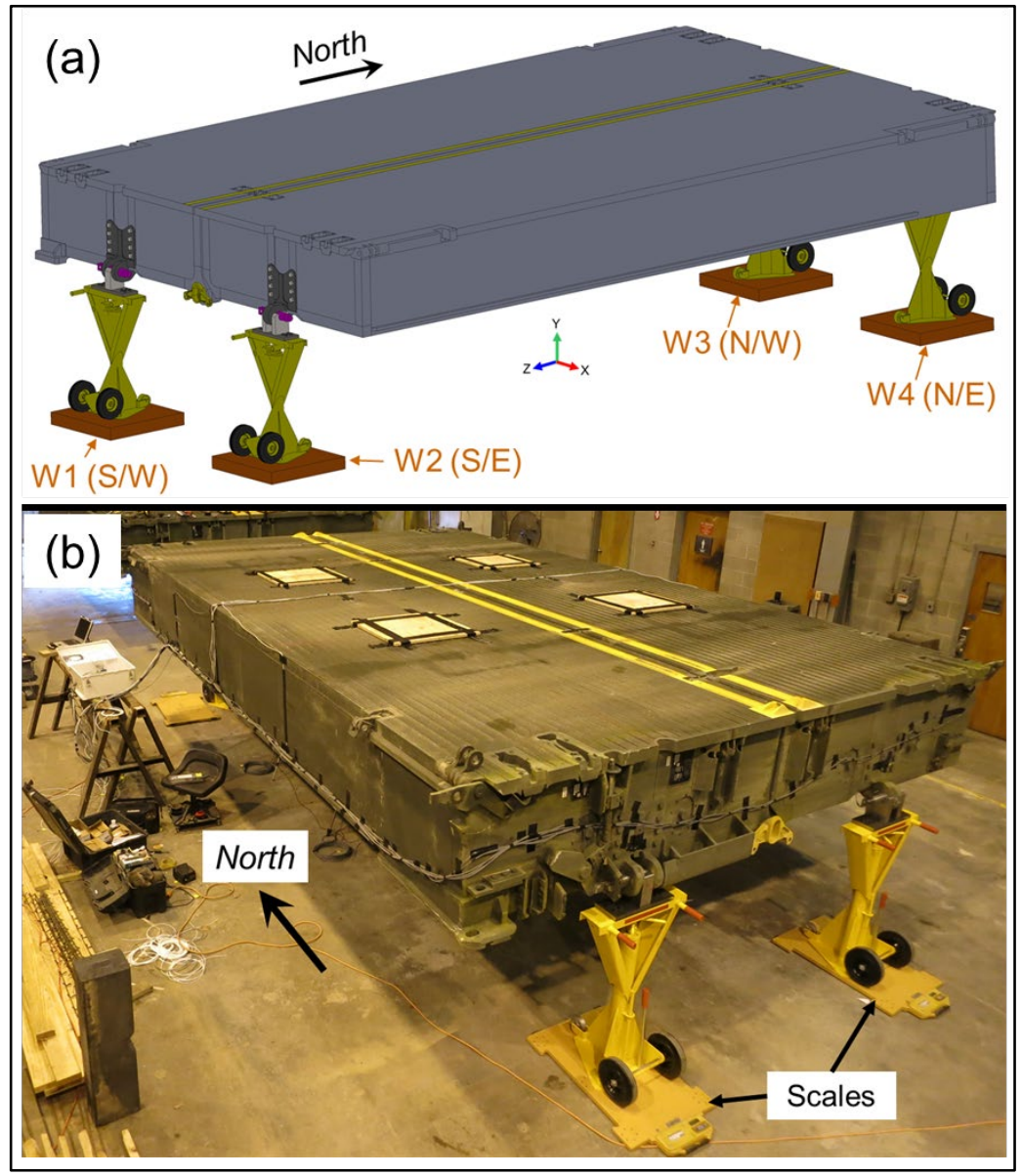


Figure 12 shows the load pin locations and orientations for the one-bay configuration in schematic fashion. Figure 13 gives photographs of the installed load pins. The load pins were zeroed prior to installation, so they read absolute load on the pin. Each load pin measures force in two axes, the $\mathrm{Y}$-axis being vertical and the $\mathrm{Z}$-axis being longitudinal (i.e., north/south).

Figure 12. Load pin locations and orientations for one-bay configuration.

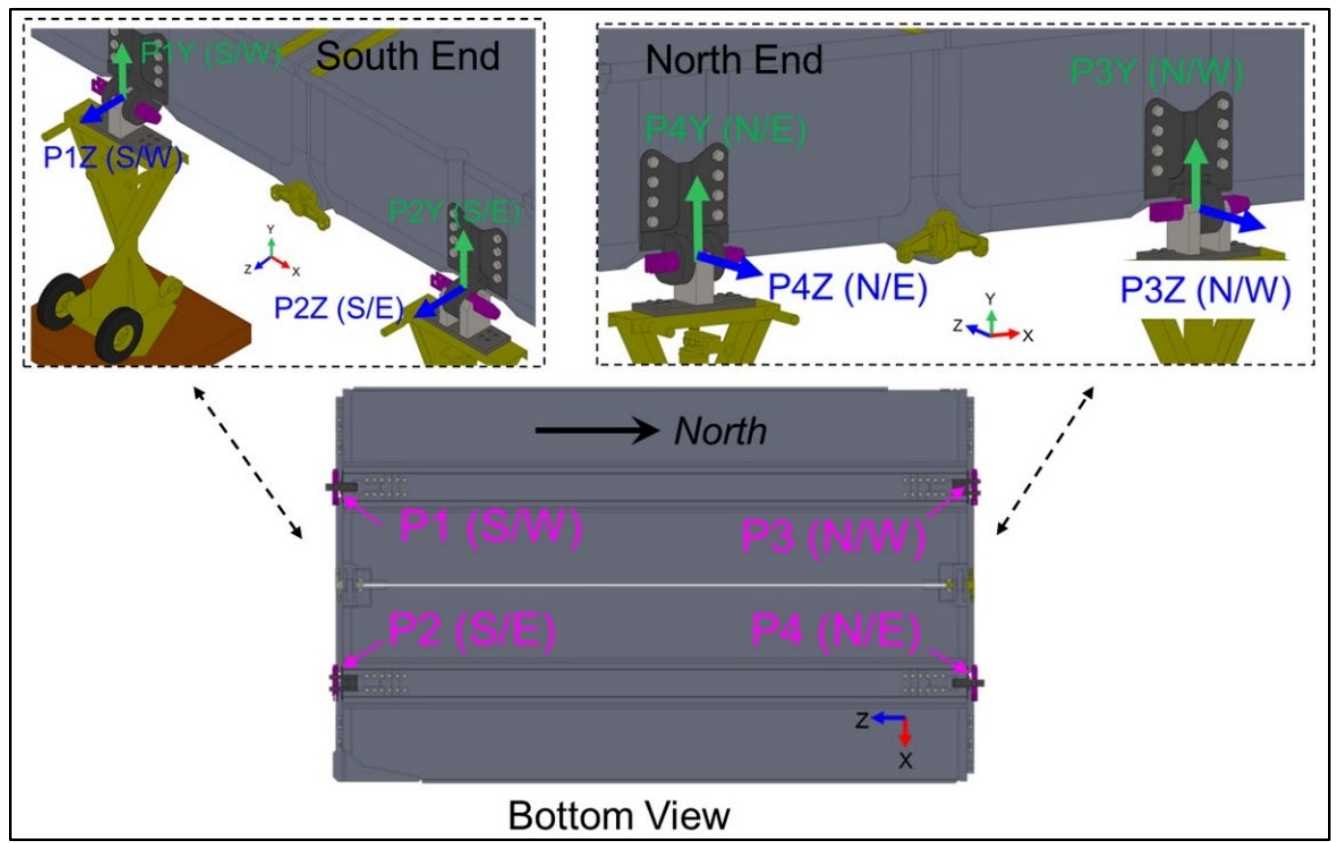

Figure 13. Load pins (a) installed in single clevis (P2 shown), (b) installed in double clevis (P1 shown), and (c) side view showing axis orientations.

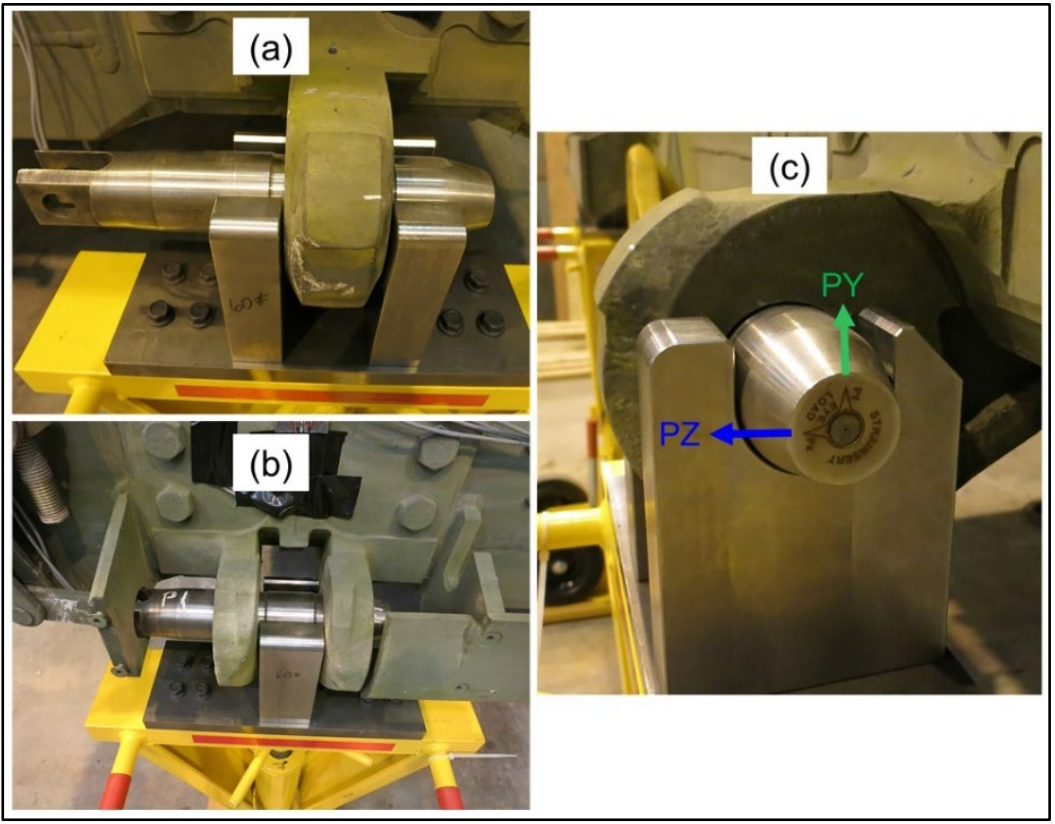


Figure 14 gives the LVDT locations. Each LVDT was mounted on a tripod underneath the bay and measured vertical (Y-axis) displacement. D1 (E) and D2 (W) were centered on the bottom of each ponton. D3 (S/W) and D4 (N/W) were transversely centered on the west ponton, $52.25 \mathrm{in}$. south and north of center, respectively. D5 (N) monitored displacement near the north supports and was transversely centered on the bay.

Figure 14. Displacement transducer locations for one-bay configuration:

(a) schematic and (b) photograph.

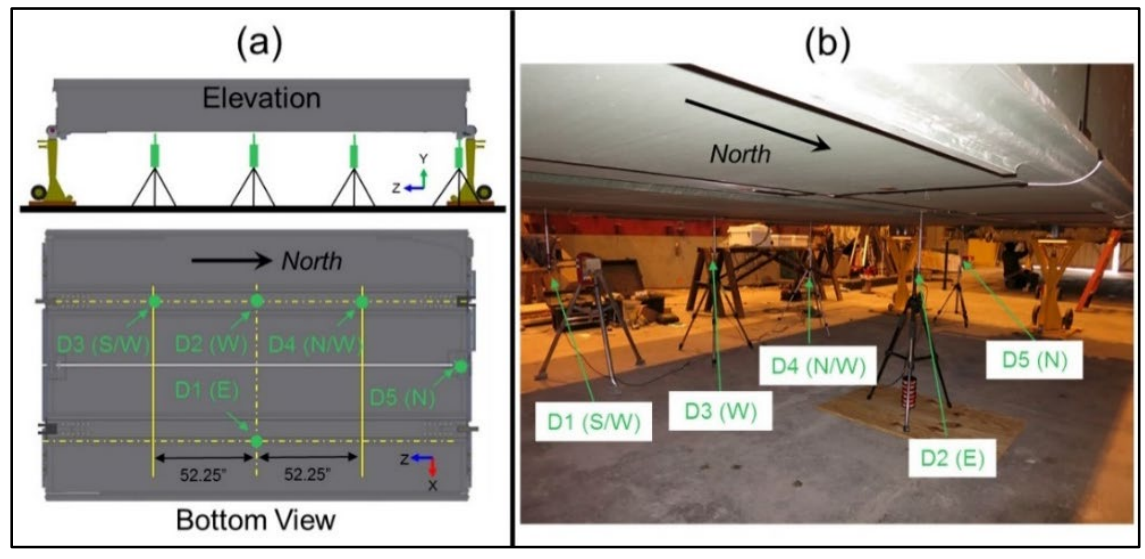

Figure 15 shows the strain gauge locations for the one-bay configuration. Rosettes are designated with prefix "SR." Four rosettes were used in the single bay tests. All rosettes were centered on the IRB main couplings, which are made of steel. Each rosette comprises three independent, stacked, axial gauges positioned at $45^{\circ}$ relative to each other. The suffixes " $A$ ", "B", and " $C$ " indicate the orientation of each grid; where, " $A$ " denotes the grid is vertical (the $\mathrm{Y}$-axis), " $\mathrm{B}$ " is at $45^{\circ}$, and " $\mathrm{C}$ " is horizontal (the $\mathrm{X}$-axis).

Figure 15. Strain gauge locations for one-bay configuration.

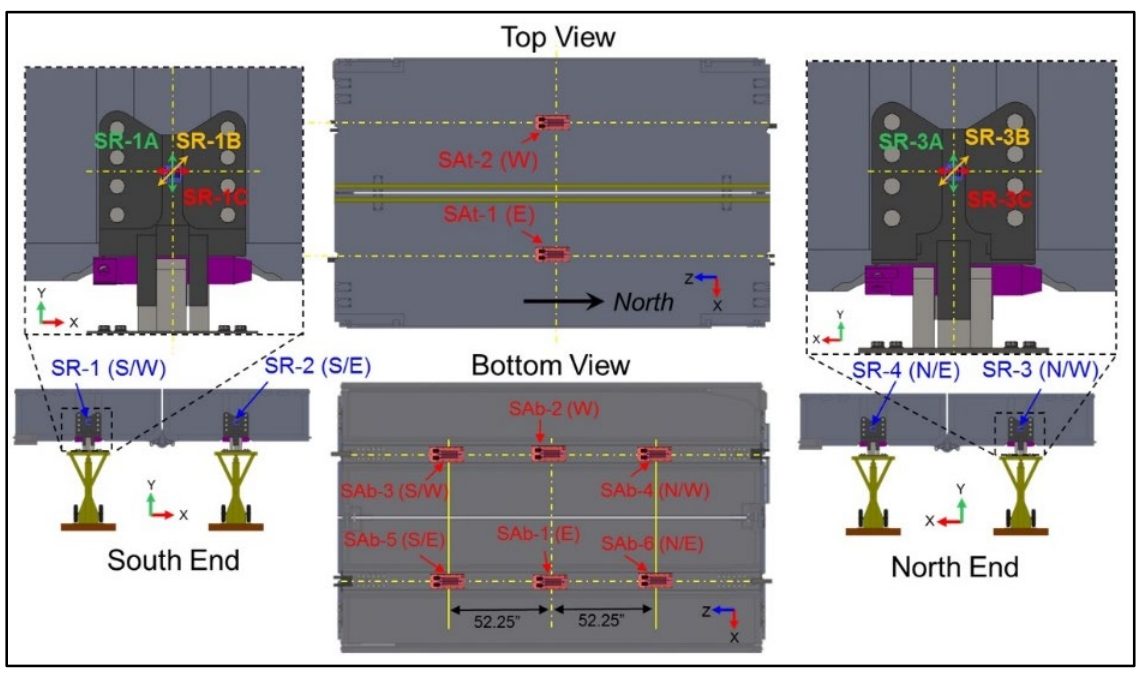


The uniaxial strain gauges have the prefix “SA.” Eight uniaxial strain gauges were installed, all on aluminum sections and all oriented in the longitudinal (Z-axis) direction. Two were centered on the top deck of each ponton (SAt-1 and SAt-2). The remaining six axial strain gauges (SAb-1 through SAb-6) were located on the bottom, transversely centered on each ponton on a continuous structural beam, similar to an I-beam flange, which longitudinally traverses the entire bridge. The main couplings bolt directly into this significant structural member.

\subsubsection{Two-bay configuration}

Figure 16 shows the weigh scale locations for two-bay configuration. Just as with the one-bay setup, a scale was placed under each support stand and zeroed with only the weight of the pin support and stabilizing stand on it. As described in section 2.2.2, the center support was only used to initially level the decks of the two bays. For testing, the center jack was lowered such that it did not contact the bridge.

Figure 16. Weigh scale locations for two-bay configuration.

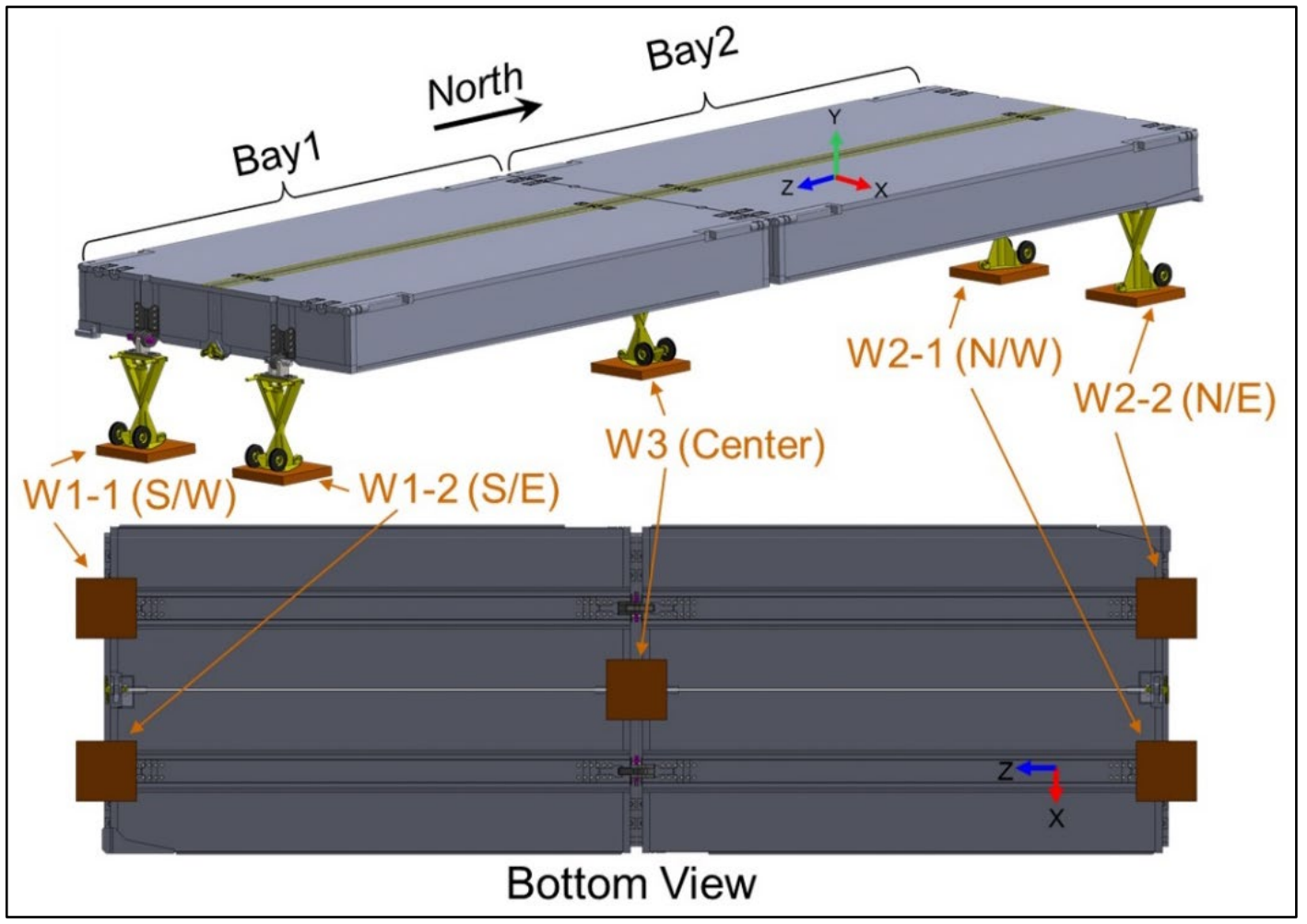


Figure 17 shows the load pin locations and orientations for the two-bay configuration. As before, the load pins were zeroed prior to installation, so they read absolute load. Load pin P1 (S/W) was located on the southwest support for bay 1. Pin P2 (N/E) was located at the opposite support (on the northeast end of bay 2). Pins $\mathrm{P}_{3}(\mathrm{~W})$ and $\mathrm{P}_{4}$ (E) measured the vertical (Y-axis) and horizontal (Z-axis) forces on the pins connecting the two bays.

Figure 17. Load pin locations for two-bay configuration.

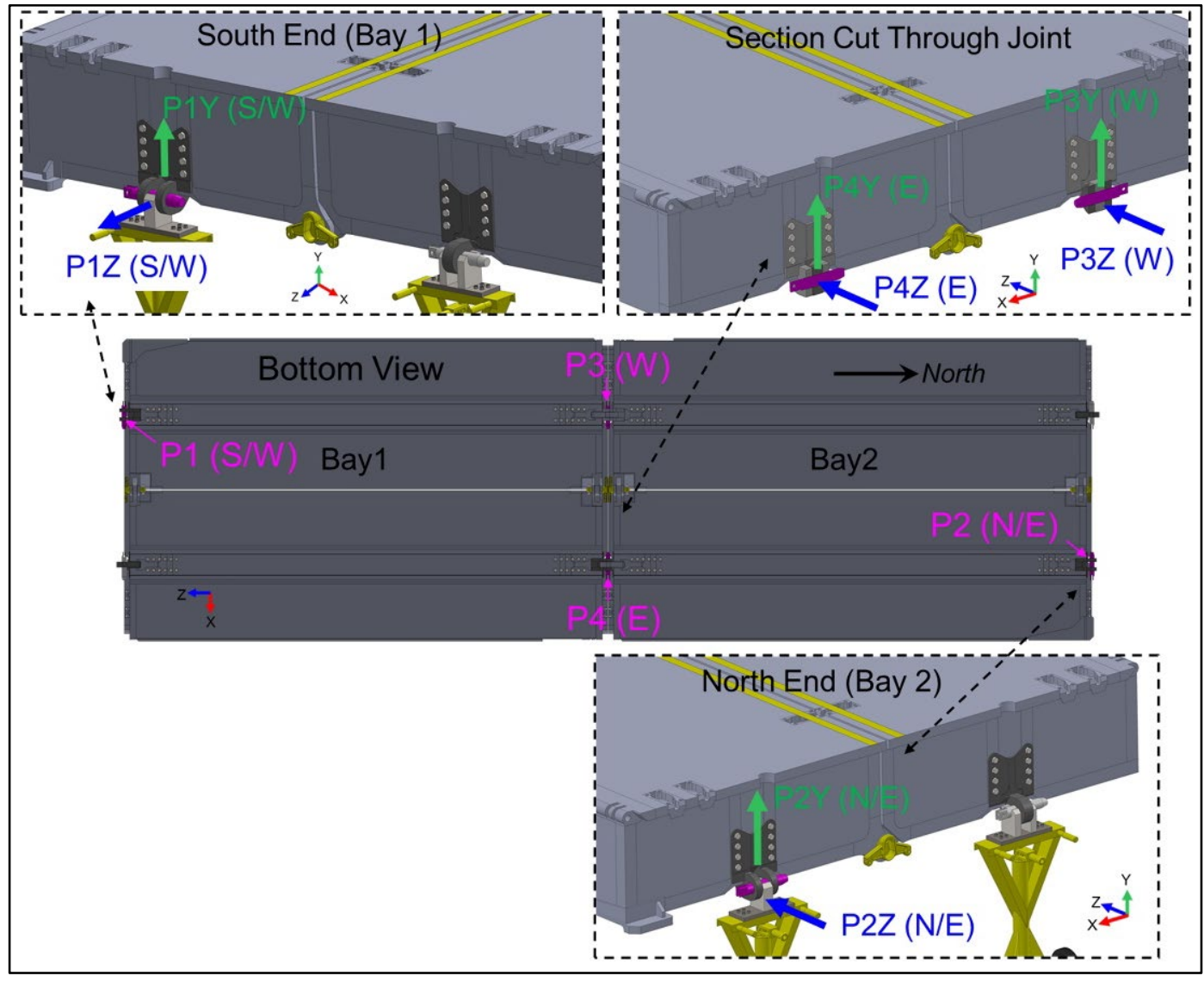

Figure 18 shows the displacement sensor locations for the two-bay configuration. Each LVDT was mounted on a tripod underneath the bay and measured vertical (Y-axis) displacement, just as in the single bay configuration. D2 (E) and D3 (W) were located underneath pins P3 (E) and $\mathrm{P} 4$ (W), respectively. D1-1 (E) and D1-2 (W) were on the bottom, center of bay 1, and D2-1 (E) was centered on the east ponton of bay 2. 
Figure 18. Displacement transducer locations for two-bay configuration.

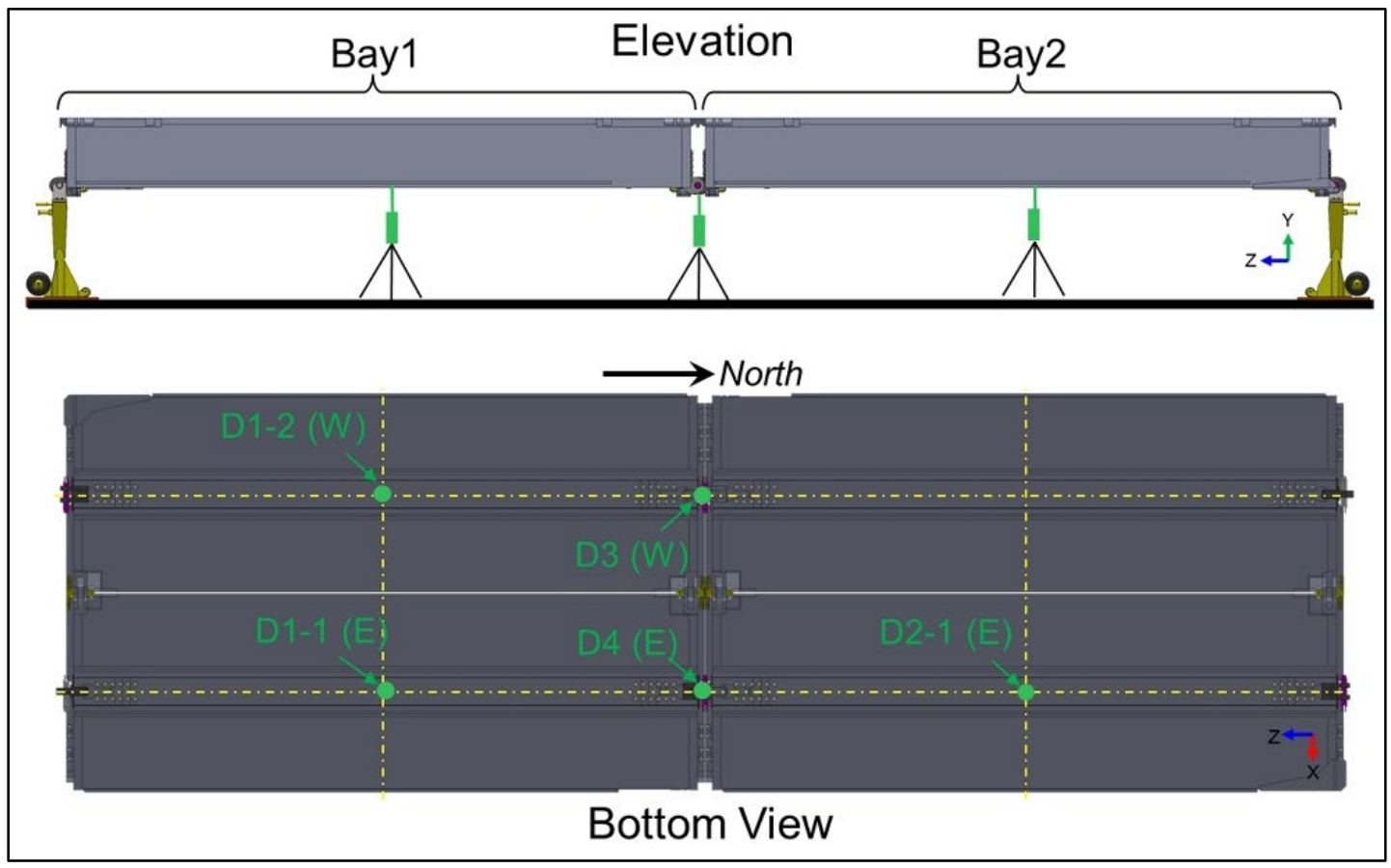

Figure 19 shows the strain gauge locations for the two-bay configuration. The strain gauges on bay 1 are the same gauges previously installed for the single bay tests. They were renamed to SR1-x (for rosettes) or SA1-x (for axial gauges) to indicate their attachment to bay 1 . The second bay was implemented with a set of strain gauges identical to the first bay with the exception that no rosettes were installed on the south flanges. These gauges were deemed unnecessary since the strains in those flanges would be redundant to those in the north end flanges of bay 1 .

Figure 19. Strain gauge locations for two-bay configuration.

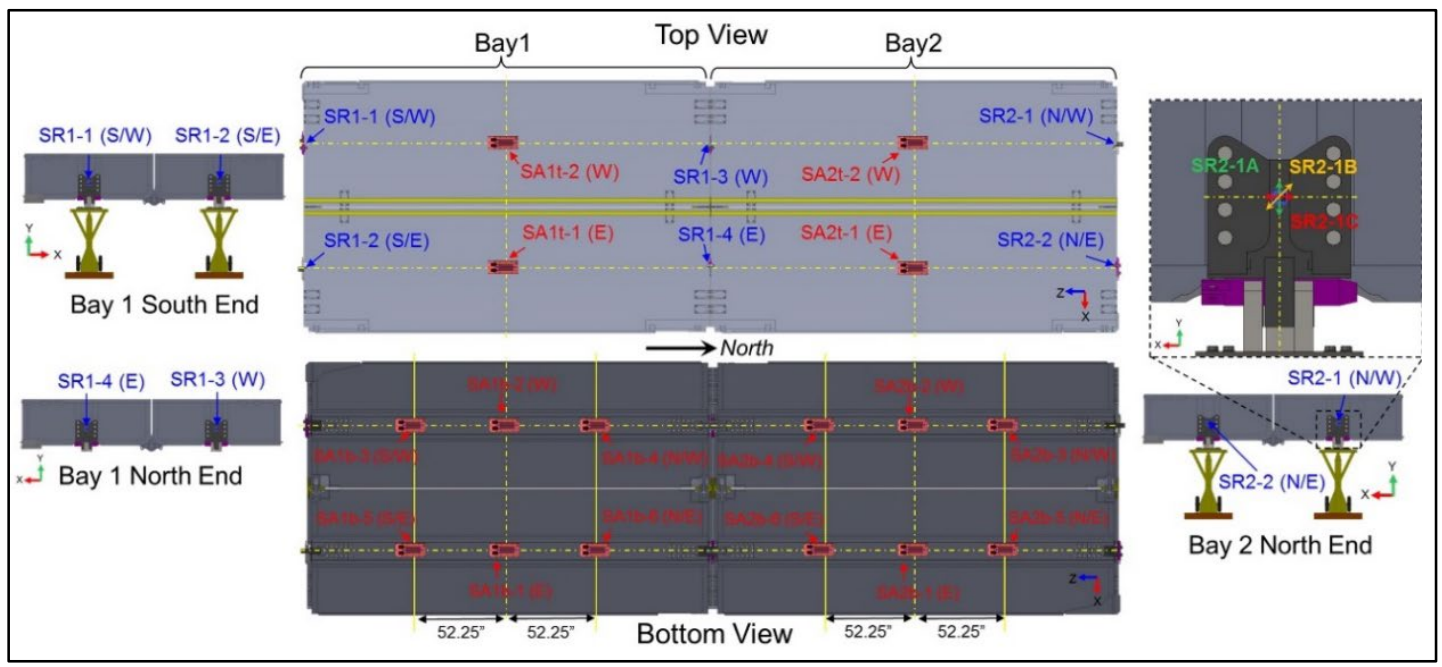




\section{Summary: Test Results and Discussion}

The IRB component weights, measured with the dynamometer, are tabulated in Table 2. Each IRB bay comprises four pontons: two inner (roadway) pontons, and two outer (bow) pontons. The inner pontons make up approximately $65 \%$ of the total weight of a bay. The outer pontons weigh less, as they contain less load bearing structure compared to the inner pontons. Each of the two bays used for this test series had a total weight of $14,000 \mathrm{lb}$. With the outer pontons removed, the inner sections weighed 9,00o lbf.

Table 2. IRB component weights.

\begin{tabular}{|c|c|c|}
\hline IRB Component & Quantity/IRB Bay & Weight (lbf) \\
\hline Inner Ponton & 2 & 4,500 \\
Outer Ponton & 2 & 2,500 \\
\hline Entire IRB Bay & 1 & 14,000 \\
\hline
\end{tabular}

\subsection{One-bay test series}

All of the single-bay tests were conducted the afternoon of 2 March 2018. Figure 20 illustrates the testing sequence via a plot of the vertical (Y-axis) load pin and displacement data collected for all of the single-bay tests (1-1, 1-2, and 1-3).

Data collection began around 13:05. At this time, the bay was supported, but no additional dead load had yet been placed on the deck. This served as the reference state (i.e., all displacement (and strain) measurements are relative to the bay under its self-weight). The vertical load measured by each load pin was initially approximately $2,250 \mathrm{lbf}$. The vertical load components for the four pins sum to approximately 9,000 lbf, the weight of the bay (with outer pontons removed).

At approximately 13:10, the first set of lead blocks for test 1-1 began being placed on the deck. It took approximately 20 min to place all four of the $\sim 4,000 \mathrm{lb}$ blocks. Once the weights for test 1-1 were in place (approximately 13:30), the structure was allowed to sit for approximately $20 \mathrm{~min}$. 
Between 13:50 and 14:10, the weights for test 1-2 were added. During this time, the dead load was doubled from $16,200 \mathrm{lb}_{\mathrm{f}}$ (test 1-1) to $32,400 \mathrm{lb}_{\mathrm{f}}$ (test 1-2). The structure was allowed to rest for the next $\sim 20 \mathrm{~min}$. At approximately 14:35, the addition of the final stack of weights began. The total load was increased to $36,560 \mathrm{lb}$ for test $1-3$. The structure was left undisturbed from 14:55 to 15:10. This hold period represents test 1-3.

Removal of the lead weights commenced at approximately 15:10. As the weights were being removed, the overhead crane being used to lift the weights from the deck had an issue and stopped responding to the controller. The issue was resolved, and the crane started working again, but because of the crane issue, it took almost 50 min to remove all of the lead weights. All of the weight was removed just prior to 16:00. This represents the unloaded state. It would be expected that all gauges would return to their initial, reference state at this time. The load pins did return to their reference values; however, for the displacement gauges, residuals ranging from -0.021 in. to -0.036 in. remained.

Figure 20. Overview of one-bay tests from 2 March 2018. Illustration of testing sequence via vertical load pin and displacement data.

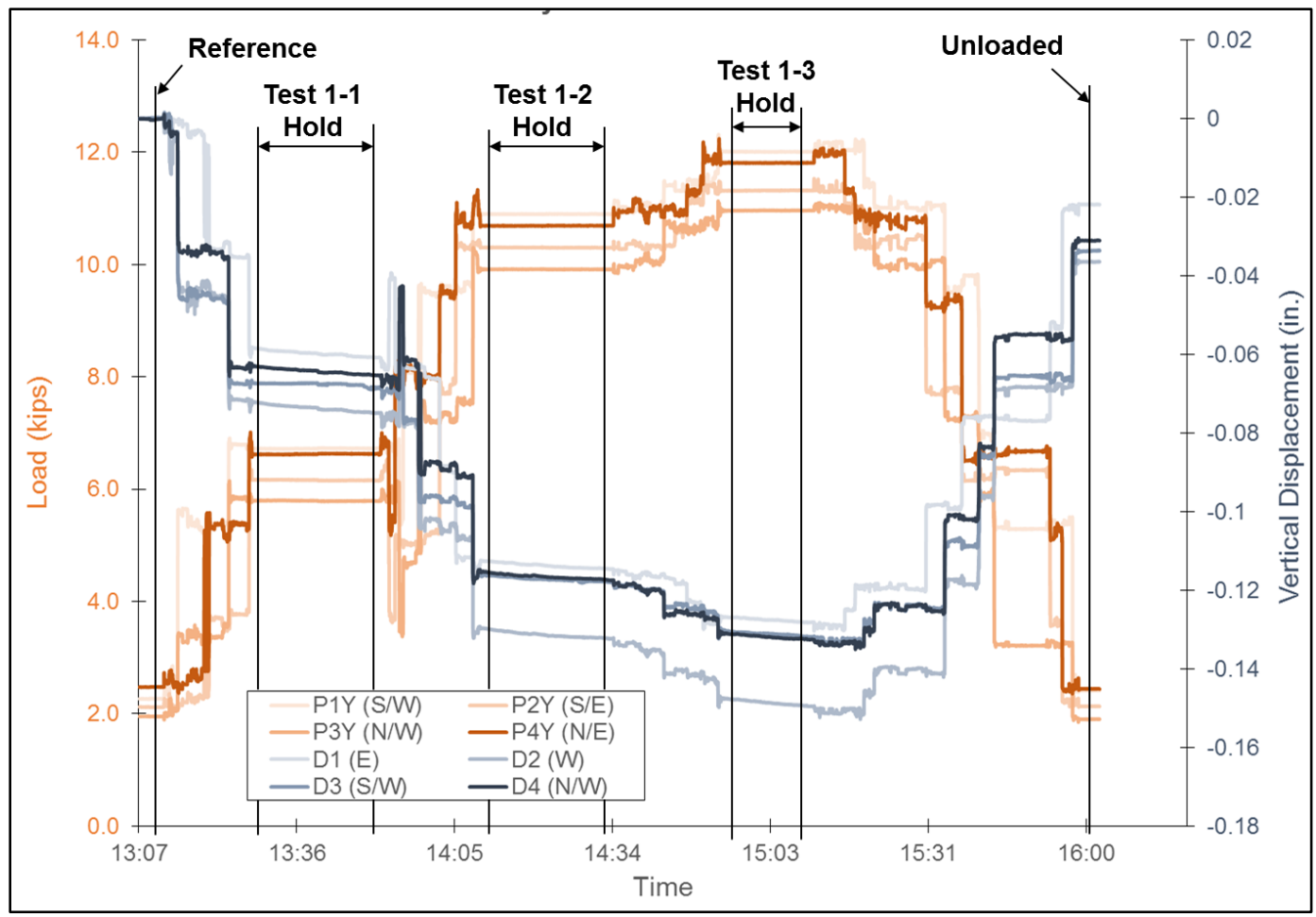


Figure 21 shows the load pin data and weighing scale data for the single-bay test series. The scale readings show excellent agreement with the vertical load pin data. As expected, the horizontal (Z-component) loads in the pins remain nearly zero for all of the one-bay tests. Also, all of the load pins returned to their initial values after unloading.

Figure 21. One-bay load pin and weighing scale data collected 2 March 2018.

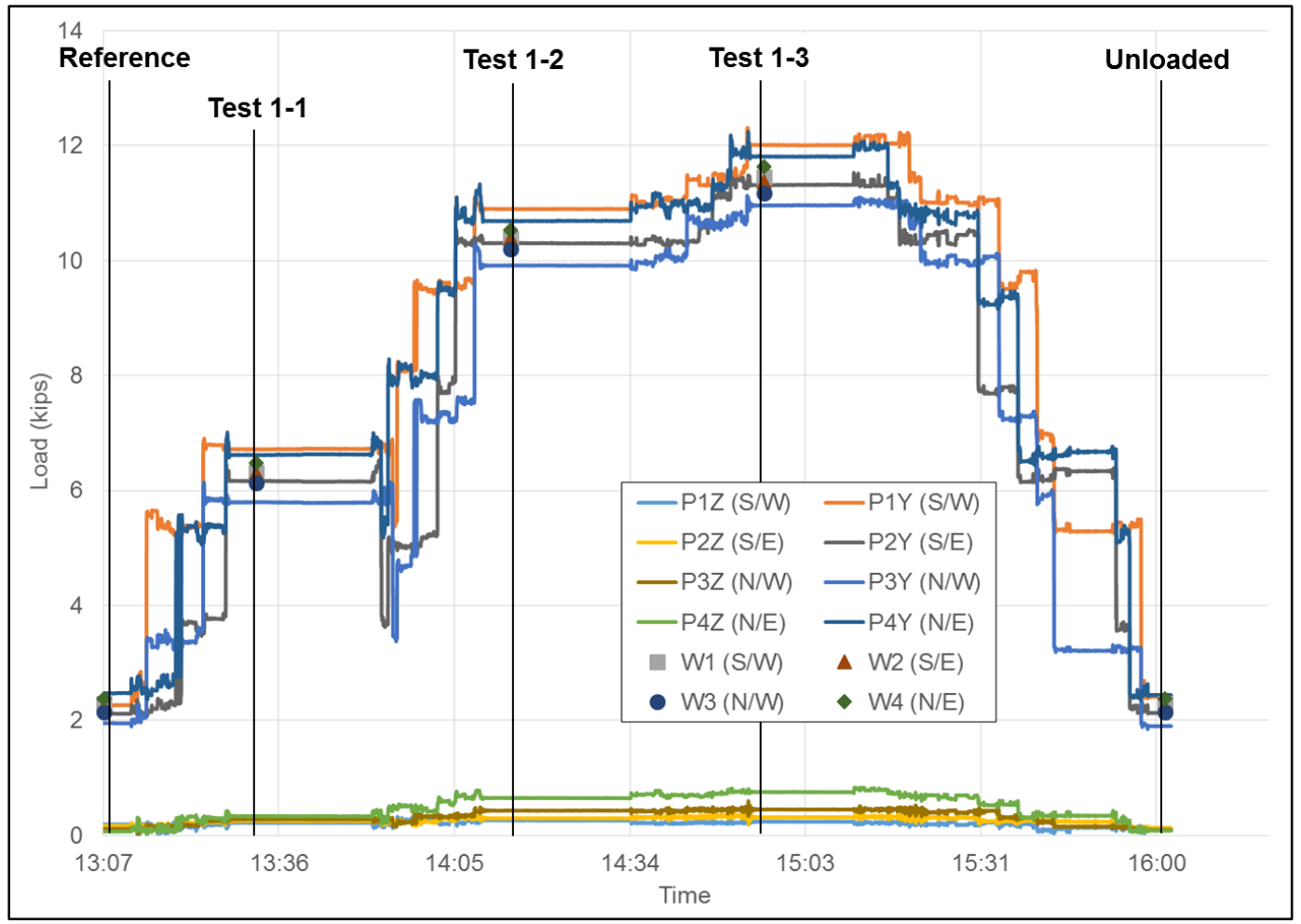

Displacement data for the one-bay configuration are plotted in Figure 22. Due to symmetry, one would expect D1 (E) and D2 (W) to give similar responses. The same is true for $\mathrm{D}_{3}(\mathrm{~S} / \mathrm{W})$ and $\mathrm{D}_{4}(\mathrm{~N} / \mathrm{W})$. Furthermore, it would be expected that the maximum displacement would occur midbay, at the D1 and D2 gauge locations. Finally, each gauge should return to its initial, reference value at the end of the day, when all the load has been removed.

Unfortunately, there appear to be a few nonphysical inconsistencies with the displacement data. The displacement from gauge D1 (E) is approximately 20\% lower than gauge D2 (W) for each load case. The displacement magnitude for D1 is smaller than D3 and D4. This is nonphysical and should be considered when finite element correlation is performed. Post unloading, residual displacements of -0.022 in., -0.037 
in., -0.034 in., and -0.031 in. exist for D1 - D4, respectively. The cause of these residual displacements is uncertain. Potential causes could be creep of the structure or the supports, movement of the displacement gauge tripods, or some combination thereof.

However, the responses of $\mathrm{D}_{3}(\mathrm{~S} / \mathrm{W})$ and $\mathrm{D} 4(\mathrm{~N} / \mathrm{W})$ show excellent agreement, providing increased confidence in those measurements. Also, D5 $(\mathrm{N})$ returns almost exactly to its initial zero after the completion of testing.

Figure 22. One-bay displacement data collected 2 March 2018.

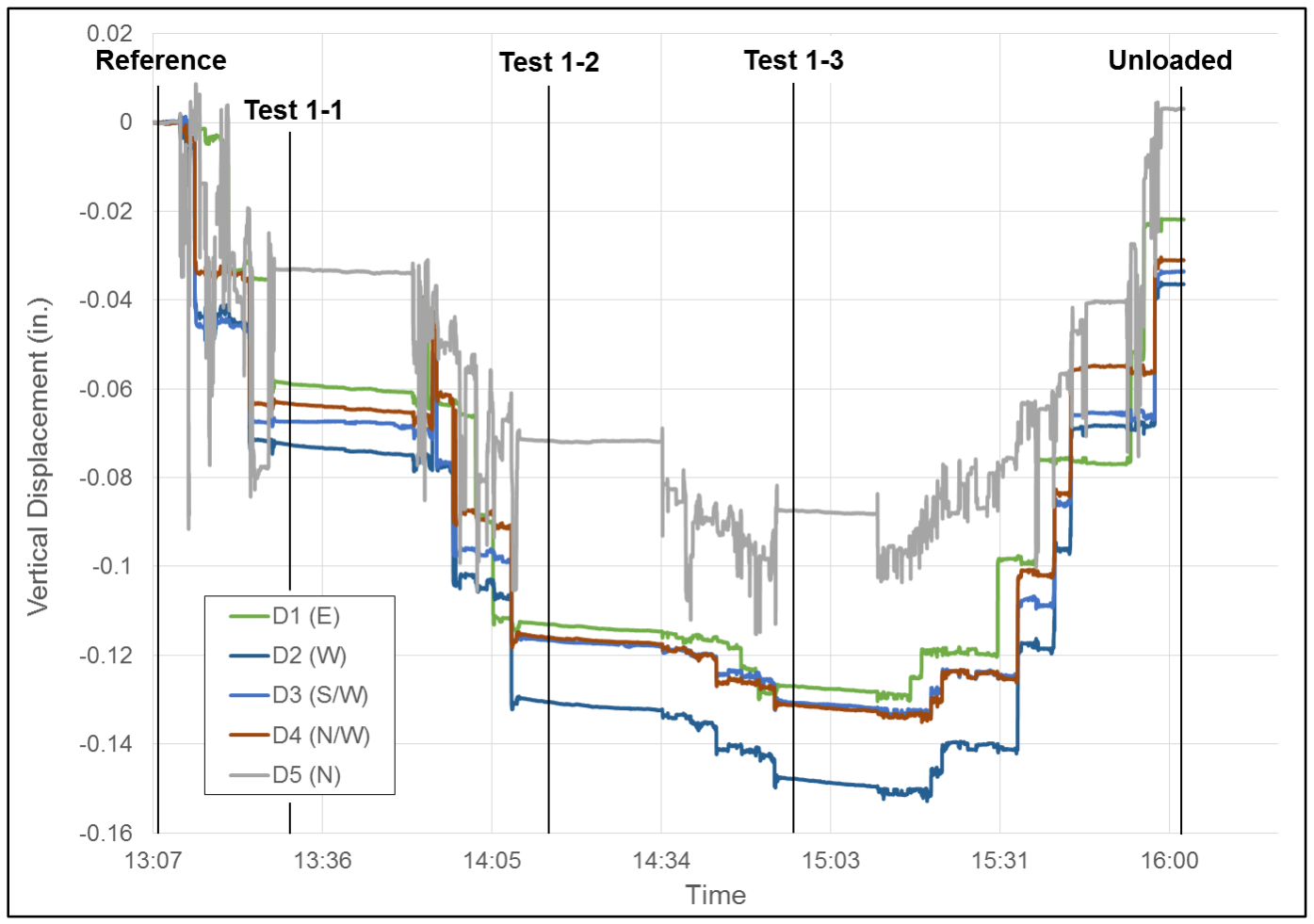

Figure 23 is a plot of all the strain gage data collected during the single-bay test series. The majority of the strain data looks reasonable. The exceptions include gauges SAb-2 (W), SAb-5 (S/E), and SAb-6 (N/E). These gauges show drift, which is attributed to imperfect adhesion to the aluminum, which was revealed during post-test inspection. These three gauges were replaced prior to conducting the two-bay tests.

The two uniaxial gages on the top deck (SAt-1 and SAt-2) show excellent agreement and indicate compression (negative strain) in the middle of the deck, as expected. The bottom flange is in tension due to the bending load, 
as indicated by positive strain in the gauges on the bottom. SAb-3 (S/W) and SAb-4 (N/W) show excellent correlation, as expected due to symmetry.

Each of the four rosettes also demonstrate superb agreement. All four of the vertically oriented grids (SR-xA) show compression under load. SR-1 and SR-4 on the southwest and northeast couplings, which both have a double clevis display virtually identical responses. All three grids on SR1 (S/W) agree with their corresponding grid on $\mathrm{SR}_{4}(\mathrm{~N} / \mathrm{E})$ to within 5 microstrain for all three tests. SR2 (S/E) and SR3 (N/W), attached to the single clevis couplings follow each other and show slightly higher strain magnitudes compared to the double clevis. This makes sense considering the load is more concentrated for the single clevis compared to the double clevis. All of the vertically orientated grids (SR-xA) measured compressive strains in the main coupling flanges under load. All horizontal grids (SR-xC) showed tensile strain in the $\mathrm{x}$-direction, with lower magnitudes compared to the y-direction.

Figure 23. One-bay strain data collected 2 March 2018.

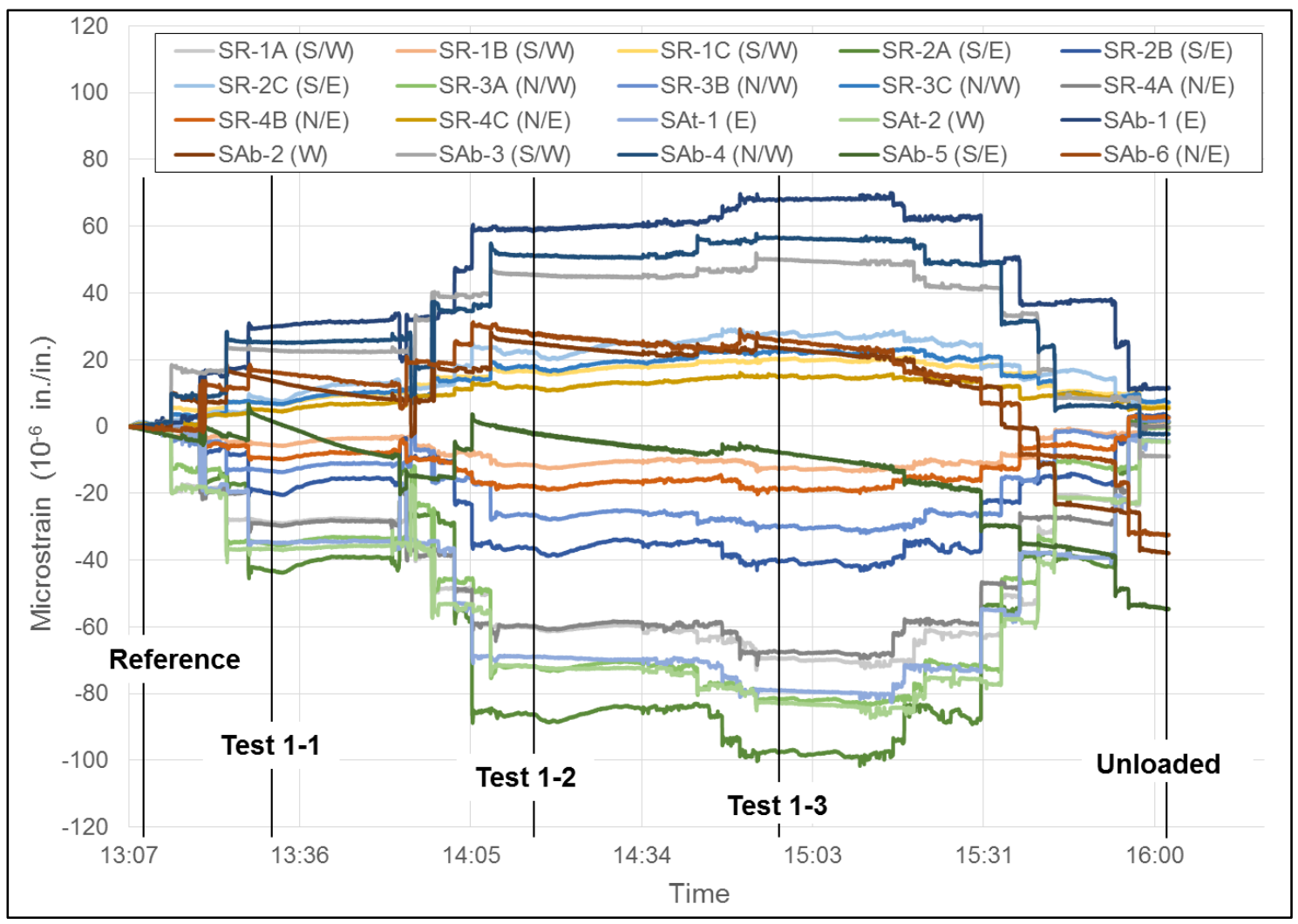


Table 3 presents the reduced data for the one-bay test series. These snapshots in time are provided to facilitate comparison to the computer simulation results.

Table 3. One-bay test series reduced data.

\begin{tabular}{|c|c|c|c|c|c|c|}
\hline & & Reference & Test 1-1 & Test 1-2 & Test 1-3 & Unloaded \\
\hline \multicolumn{2}{|c|}{ Time: } & 13:08 & $13: 33$ & $14: 14$ & $14: 56$ & 16:02 \\
\hline \multicolumn{2}{|c|}{ Added Weight (lbf.): } & 0 & 16,200 & 32,400 & 36,560 & 0 \\
\hline Gauge Type & Gauge ID & \multicolumn{5}{|c|}{ Measurement } \\
\hline \multirow{4}{*}{$\begin{array}{c}\text { Load Pin } \\
\text { Z-Components } \\
\text { (Ibf. })\end{array}$} & P1Z (S/W) & 190.7 & 217.2 & 262.8 & 244.2 & 96.3 \\
\hline & P2Z (S/E) & 162.1 & 251.5 & 297.8 & 315.4 & 133.6 \\
\hline & P3Z (N/W) & 111.7 & 279.6 & 429.8 & 450.8 & 94.5 \\
\hline & P4Z (N/E) & 65.8 & 333.0 & 651.1 & 757.1 & 85.9 \\
\hline \multirow{4}{*}{$\begin{array}{c}\text { Load Pin } \\
\text { Y- Components } \\
\text { (Ibf. })\end{array}$} & $\mathrm{P} 1 \mathrm{Y}(\mathrm{S} / \mathrm{W})$ & 2264.3 & 6718.5 & 10897.8 & 12014.3 & 2411.2 \\
\hline & $\mathrm{P} 2 \mathrm{Y}(\mathrm{S} / \mathrm{E})$ & 2121.2 & 6167.4 & 10307.5 & 11317.2 & 2134.4 \\
\hline & P3Y (N/W) & 1950.2 & 5797.9 & 9924.7 & 10964.5 & 1904.0 \\
\hline & P4Y (N/E) & 2472.6 & 6619.7 & 10686.3 & 11812.3 & 2442.2 \\
\hline \multirow{4}{*}{ Weigh Scales ( $\left(\mathrm{lb}_{\mathrm{f} .}\right)$} & W1 (S/W) & 2300 & 6320 & 10380 & 11460 & 2300 \\
\hline & W2 (S/E) & 2220 & 6300 & 10380 & 11380 & 2220 \\
\hline & W3 (N/W) & 2140 & 6140 & 10200 & 11180 & 2140 \\
\hline & W4 (N/E) & 2380 & 6480 & 10540 & 11640 & 2380 \\
\hline \multirow{5}{*}{$\begin{array}{l}\text { Displacement } \\
\text { Transducers (in.) }\end{array}$} & $\mathrm{D} 1(\mathrm{E})$ & 0 & -0.0591 & -0.1130 & -0.1270 & -0.0219 \\
\hline & $\mathrm{D} 2(\mathrm{~W})$ & 0 & -0.0729 & -0.1305 & -0.1478 & -0.0365 \\
\hline & D3 (S/W) & 0 & -0.0674 & -0.1163 & -0.1306 & -0.0336 \\
\hline & D4 (N/W) & 0 & -0.0636 & -0.1160 & -0.1312 & -0.0311 \\
\hline & D5 (N) & 0 & -0.0331 & -0.0717 & -0.0875 & 0.0030 \\
\hline \multirow{12}{*}{$\begin{array}{l}\text { Strain Gauge } \\
\text { Rosettes }(\mu \varepsilon)\end{array}$} & $\mathrm{SR}-1 \mathrm{~A}(\mathrm{~S} / \mathrm{W})$ & 0 & -28.94 & -60.07 & -69.35 & -4.54 \\
\hline & SR-1B (S/W) & 0 & -5.63 & -11.54 & -12.34 & 1.41 \\
\hline & $\mathrm{SR}-1 \mathrm{C}(\mathrm{S} / \mathrm{W})$ & 0 & 6.87 & 16.68 & 20.22 & 6.38 \\
\hline & SR-2B (S/E) & 0 & -43.58 & -85.82 & -97.08 & 1.91 \\
\hline & SR-2A (S/E) & 0 & -20.19 & -35.93 & -40.00 & 3.83 \\
\hline & SR-2C (S/E) & 0 & 7.64 & 22.54 & 28.24 & 7.80 \\
\hline & SR-3A (N/W) & 0 & -35.54 & -71.53 & -81.38 & -0.26 \\
\hline & SR-3B (N/W) & 0 & -13.65 & -26.30 & -29.74 & 2.00 \\
\hline & SR-3C (N/W) & 0 & 6.81 & 18.16 & 22.36 & 7.80 \\
\hline & SR-4A (N/E) & 0 & -29.63 & -59.56 & -67.32 & 0.21 \\
\hline & SR-4B (N/E) & 0 & -9.68 & -17.61 & -18.48 & 3.02 \\
\hline & SR-4C (N/E) & 0 & 4.67 & 12.13 & 15.25 & 5.72 \\
\hline
\end{tabular}




\begin{tabular}{|c|c|c|c|c|c|c|}
\cline { 3 - 7 } \multicolumn{2}{c|}{} & Reference & Test 1-1 & Test 1-2 & Test 1-3 & Unloaded \\
\hline \multirow{4}{*}{} & SAt-1 (E) & 0 & -34.86 & -68.99 & -79.02 & -4.23 \\
\cline { 2 - 7 } & SAt-2 (W) & 0 & -36.70 & -71.86 & -82.71 & -4.45 \\
\cline { 2 - 7 } & SAb-1 (E) & 0 & 30.08 & 59.12 & 68.06 & 11.52 \\
\cline { 2 - 7 } $\begin{array}{c}\text { Uniaxial Strain } \\
\text { Gauges }(\mu \varepsilon)\end{array}$ & SAb-2 (W) & 0 & 13.34 & 25.17 & 23.56 & -37.53 \\
\cline { 2 - 7 } & SAb-3 (S/W) & 0 & 22.67 & 45.53 & 50.03 & -8.85 \\
\cline { 2 - 7 } & SAb-4 (N/W) & 0 & 25.09 & 51.15 & 56.46 & -7.25 \\
\cline { 2 - 7 } & SAb-5 (S/E) & 0 & 0.89 & -1.83 & 28.52 & -54.40 \\
\cline { 2 - 7 } & SAb-6 (N/E) & 0 & 16.07 & 28.40 & 26.03 & -32.14 \\
\hline
\end{tabular}

\subsection{Two-bay test series}

The two-bay test series was conducted the afternoon of 7 March 2018.

Figure 24 illustrates the testing sequence via a plot of the supported vertical (Y-axis) load pins and vertical displacement data at the middle of the bridge span.

Data collection began at approximately 12:41. At this time, the two bays were supported at each end and also in the center, as shown in Figure 16. For this reference state (with the center supported), the decks of the two bays were level and not in contact. The LVDTs were zeroed in this configuration. The strain gages, however, were not zeroed until the center support was removed, since the center support would induce an undesired strain field, complicating the finite element correlation study.

The center support was removed at approximately 13:00. Instrumentation checks were performed from 13:00 to approximately 13:45. The structure was then allowed to rest for approximately 5 min (from 13:45 to 13:50). This period corresponds to the reference-unsupported state from which all strain measurements are relative.

At approximately 13:50, the first set of lead blocks for test 2-1 began being placed on the deck. It took approximately $25 \mathrm{~min}$ to place all eight of the $\sim 1,000 \mathrm{lb}$ blocks. Once the weights for test 2-1 were in place (at approximately 14:15), the structure was allowed to sit for approximately $10 \mathrm{~min}$.

Between 14:30 and 15:00, the weights for test 2-2 were added. During this time, the dead load was approximately doubled from $8,280 \mathrm{lb}_{\mathrm{f}}$ (test 2-1) to $16,360 \mathrm{lb}_{\mathrm{f}}$ (test 2-2). The structure was allowed to rest for the next $\sim 15 \mathrm{~min}$. 
At approximately 15:15, the addition of the final stack of weights began. The total load was increased to $24,640 \mathrm{lb}_{\mathrm{f}}$ for test $2-3$. The structure was left undisturbed from 15:35 to 15:45. During this period, the data for test 2-3 were recorded.

Removal of the lead weights commenced at approximately 15:45. All of the weight was removed by $\sim 16: 00$. This represents the unloaded state with the center still unsupported. It would be expected that the strain gauges would return to their initial, reference state at this time. At 16:03, the center support was raised to bring the decks back to level. By 16:08, the center support was in place. This is referred to as the unloaded-supported state. At this point, it would be expected that the displacement gages would come back to zero. However, just as in the single-bay test series, residual displacements ranging from -0.038 in. to 0.032 in. remained in the gages.

Figure 24. Overview of two-bay tests from 7 March 2018. Illustration of testing sequence via supported vertical load pin and vertical displacement data at mid-bridge.

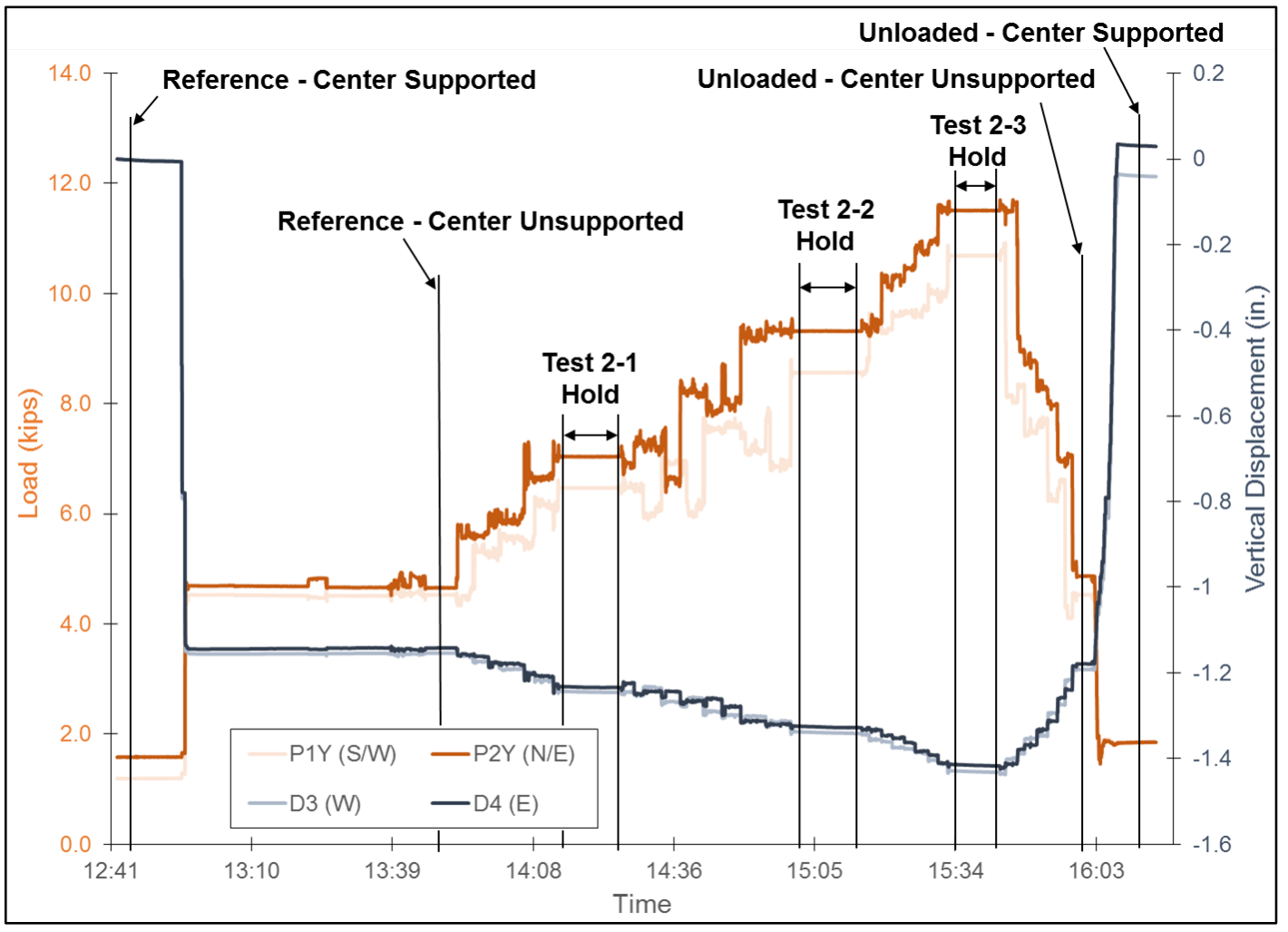


Figure 25 shows the load pin data and weigh scale data for the dual-bay test series. The scale readings show excellent agreement with the vertical load pin data. Also, all of the load pins returned to their initial values after unloading. When the center support was removed, a spike in the z-load components was observed (at 13:00) in the two pins between the IRB bays. Under only the self-weight of the bridge, each pin experienced approximately 23 kips. By the time all the weight had been added, for test 2-3, these loads increased to approximately 53 kips.

Figure 25. Two-bay load pin and weighing scale data collected 7 March 2018.

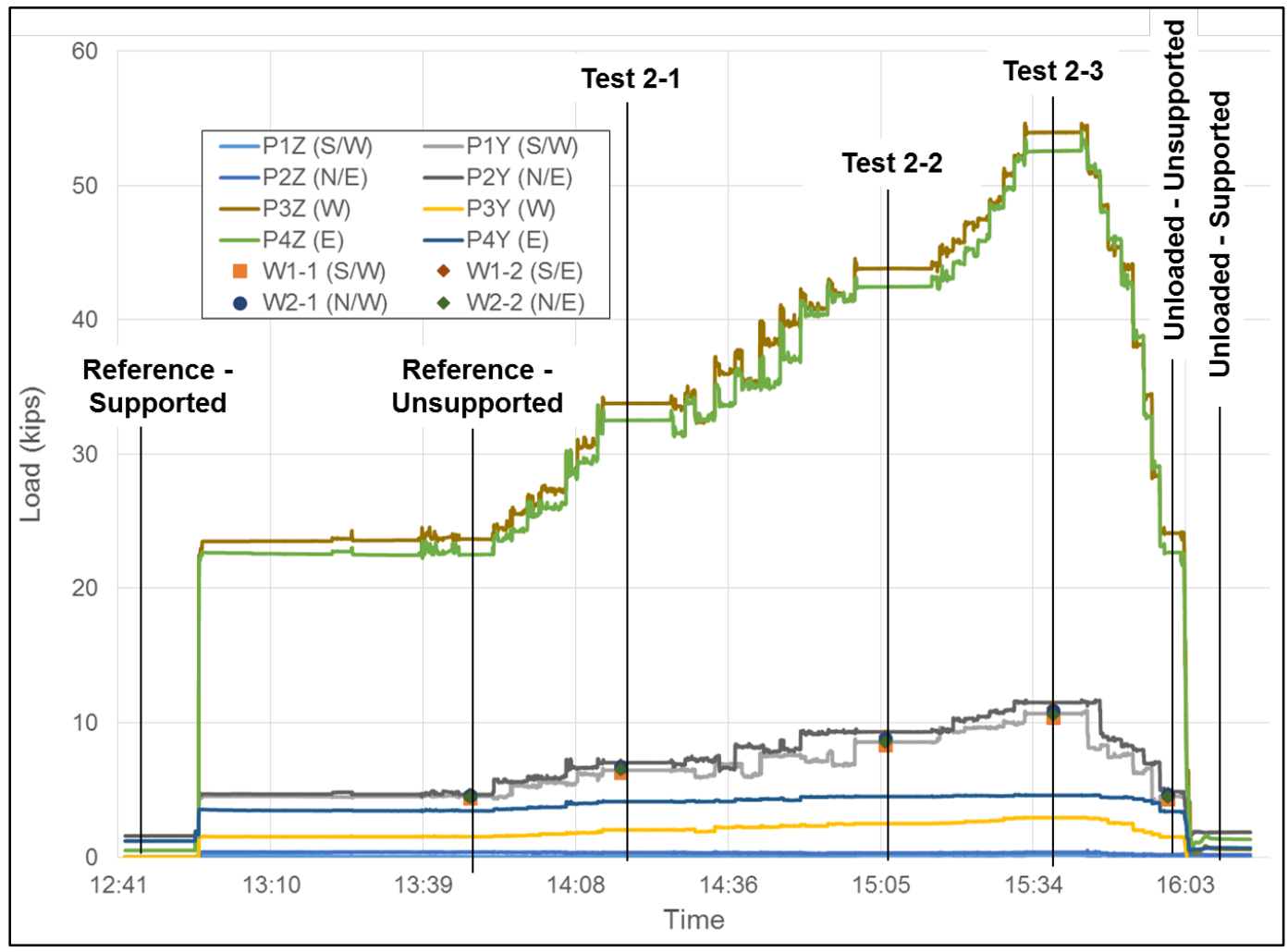

Displacement data for the one-bay configuration are plotted in Figure 26. Due to symmetry, one would expect D3 (W) and D4 (E) to give similar responses. The same is true for D1-1 (E), D1-2 (W), and D2-1 (E), so the measurements from those gages should be comparable. Furthermore, it would be expected that the maximum displacement would occur midbridge, at the D3 and D4 gauge locations. Finally, each gauge should return to its initial, reference value at the end of the day, when all the weights have been removed. For the most part, all of these expectations are observed. The only troubling part is none of the displacement gauges except D2-1 (E) returned to their reference state, post-test. 
Figure 26. Two-bay displacement data collected 7 March 2018.

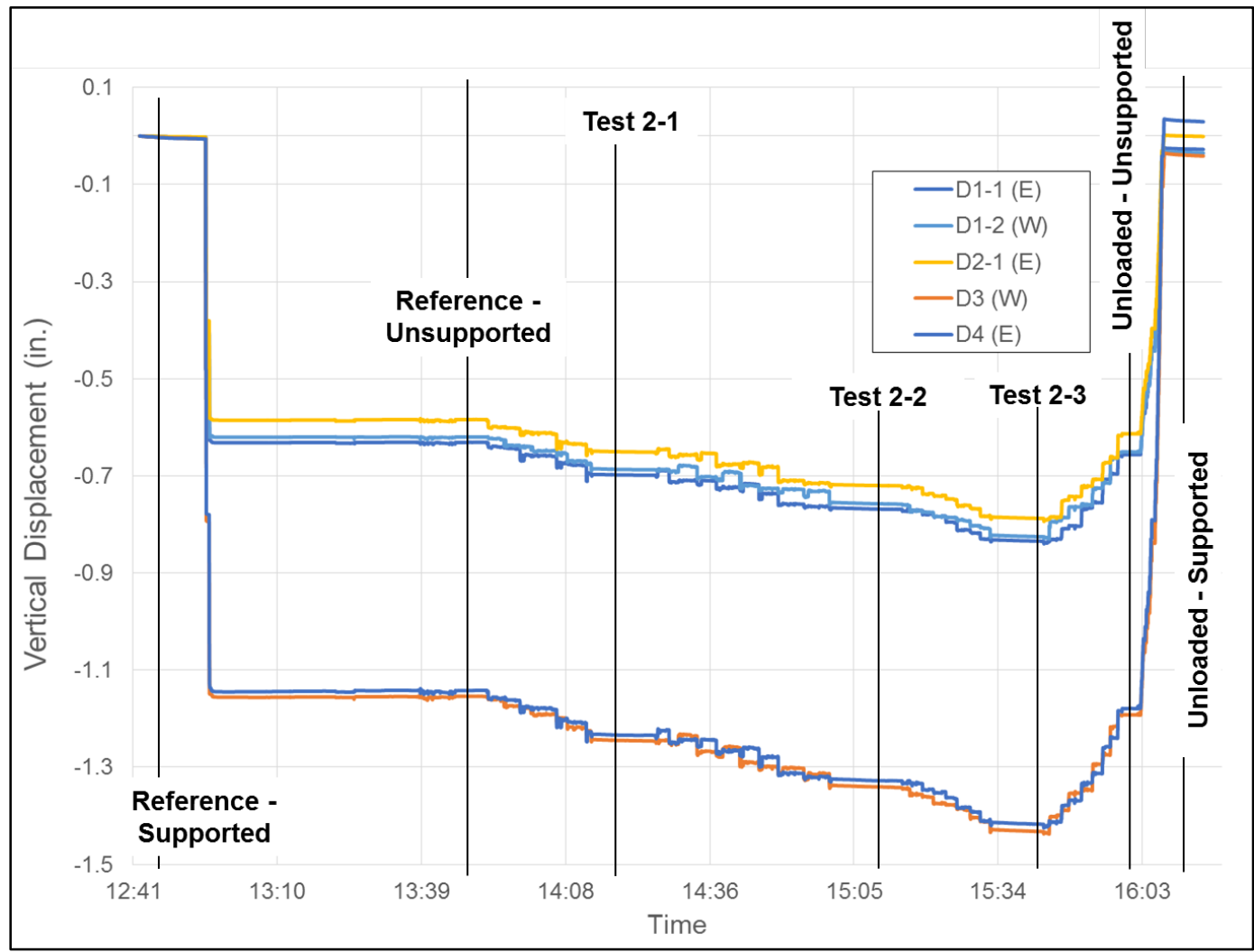

Figure 27 is a plot of all the strain gage data collected during the two-bay test series. The strain data look excellent. None of the gauges exhibit drift, which was a problem with three of the gauges during single-bay testing.

The four uniaxial gages on the top decks (SA1t-1, SA1t-2, SA2t-1, SA2t-2) show splendid agreement and indicate compression (negative strain) in the middle of the deck, as expected. The bottom flange is in tension due to the bending load, as indicated by positive strain in the gauges on the bottom. All of the strain gages on the bottom (SAxb-y) in comparable positions also correlate well.

The two rosettes located on the center, unsupported couplings (SR1-3 and SR1-4) show nearly identical responses. The vertical grids (SR1-3A and SR1-4A) show compressive strain, and the horizontal grids (SR1-3C and SR1-4C) show tensile strain, albeit of lower magnitude. Interestingly, the four rosettes on the supported ends of the bridge provide very similar responses compared to the gauges on the unsupported couplings. One might expect the strain in the unsupported couplings to be higher given the large horizontal pin loads at those locations, but this was not observed. 
Figure 27. Two-bay strain data collected 7 March 2018.

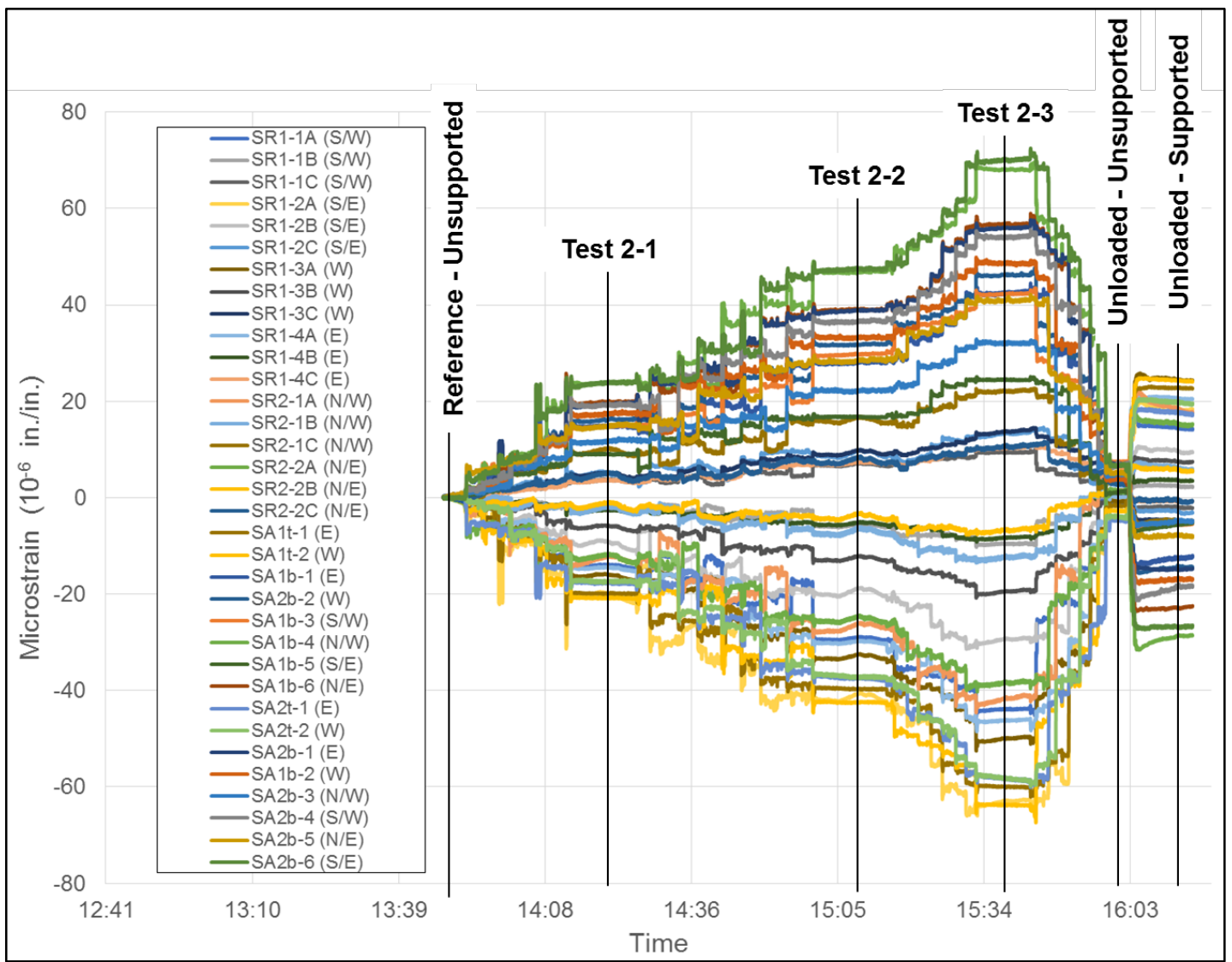

Table 4 presents the reduced data for the two-bay test series in a similar fashion as Table 3 for the one-bay test series. These snapshots in time are provided to facilitate comparison to the computer simulation results.

Table 4. Two-bay test series reduced data.

\begin{tabular}{|c|c|c|c|c|c|c|c|c|}
\hline & & $\begin{array}{l}\text { Reference - } \\
\text { Center } \\
\text { Supported }\end{array}$ & $\begin{array}{l}\text { Reference - } \\
\text { Center } \\
\text { Unsupported }\end{array}$ & Test 2-1 & Test 2-2 & Test 2-3 & $\begin{array}{l}\text { Unloaded - } \\
\text { Center } \\
\text { Unsupported }\end{array}$ & $\begin{array}{l}\text { Unloaded - } \\
\text { Center } \\
\text { Supported }\end{array}$ \\
\hline \multicolumn{2}{|c|}{ Time: } & $12: 43$ & $13: 48$ & $14: 20$ & $15: 08$ & $15: 38$ & $16: 00$ & $16: 05$ \\
\hline \multicolumn{2}{|c|}{ Added Weight (l $\mathrm{b}_{\mathrm{f}}$ ) } & 0 & 0 & 8,280 & 16,360 & 24,640 & 0 & 0 \\
\hline Gauge Type & Gauge ID & \multicolumn{7}{|c|}{ Measurement } \\
\hline \multirow{4}{*}{$\begin{array}{l}\text { Load Pin } \\
\text {-Components } \\
\text { (Ibf.) }\end{array}$} & $\mathrm{P} 1 \mathrm{Z}(\mathrm{S} / \mathrm{W})$ & 18.1 & 40.5 & 84.9 & 128.4 & 168.6 & 37.6 & 37.4 \\
\hline & $\mathrm{P} 2 \mathrm{Z}(\mathrm{S} / \mathrm{E})$ & -23.7 & 368.7 & 333.3 & 298.2 & 360.4 & 187.5 & 169.5 \\
\hline & P3Z (N/W) & -9.1 & 23673.2 & 33780.3 & 43815.9 & 53970.3 & 24128.8 & 599.5 \\
\hline & P4Z (N/E) & 497.3 & 22518.1 & 32519.0 & 42461.0 & 52572.0 & 22676.6 & 1354.8 \\
\hline
\end{tabular}




\begin{tabular}{|c|c|c|c|c|c|c|c|c|}
\hline & & $\begin{array}{l}\text { Reference - } \\
\text { Center } \\
\text { Supported }\end{array}$ & $\begin{array}{l}\text { Reference - } \\
\text { Center } \\
\text { Unsupported }\end{array}$ & Test 2-1 & Test 2-2 & Test 2-3 & $\begin{array}{l}\text { Unloaded - } \\
\text { Center } \\
\text { Unsupported }\end{array}$ & $\begin{array}{l}\text { Unloaded - } \\
\text { Center } \\
\text { Supported }\end{array}$ \\
\hline \multirow{4}{*}{$\begin{array}{l}\text { Load Pin } \\
\text { Y- Components } \\
\left(\mathrm{lb}_{\mathrm{f}}\right)\end{array}$} & $\mathrm{P} 1 \mathrm{Y}(\mathrm{S} / \mathrm{W})$ & 1193.7 & 4529.0 & 6473.6 & 8564.7 & 10693.7 & 4531.2 & 1838.7 \\
\hline & $\mathrm{P} 2 \mathrm{Y}(\mathrm{S} / \mathrm{E})$ & 1577.6 & 4654.7 & 7040.2 & 9318.1 & 11509.3 & 4873.7 & 1849.0 \\
\hline & P3Y (N/W) & 3.7 & 1530.4 & 2027.1 & 2495.5 & 2940.4 & 1502.4 & -293.3 \\
\hline & P4Y (N/E) & 1196.6 & 3439.5 & 4139.2 & 4507.8 & 4598.2 & 3386.2 & 694.3 \\
\hline \multirow{5}{*}{$\begin{array}{c}\text { Weigh Scales } \\
\quad\left(\mathrm{lb}_{\mathrm{f}}\right)\end{array}$} & $\begin{array}{l}\text { W1-1 } \\
\text { (S/W) }\end{array}$ & 1200 & 4360 & 6320 & 8340 & 10360 & 4320 & 1720 \\
\hline & W1-2 (S/E) & 3260 & 4680 & 6860 & 8980 & 11100 & 4760 & 2660 \\
\hline & $\begin{array}{l}\text { W2-1 } \\
\text { (N/W) }\end{array}$ & 2900 & 4620 & 6740 & 8820 & 10880 & 4660 & 2640 \\
\hline & W2-2 (N/E) & 1620 & 4480 & 6540 & 8560 & 10640 & 4440 & 1800 \\
\hline & $\begin{array}{c}\text { W3 } \\
\text { (Center) }\end{array}$ & 9140 & 0 & 0 & 0 & 0 & 0 & 9320 \\
\hline \multirow{5}{*}{$\begin{array}{l}\text { Displacement } \\
\text { Transducers } \\
\text { (in.) }\end{array}$} & D1-1 (E) & 0 & -0.631 & -0.697 & -0.767 & -0.833 & -0.656 & -0.026 \\
\hline & D2-1 (E) & 0 & -0.584 & -0.650 & -0.719 & -0.786 & -0.613 & 0.000 \\
\hline & D1-2 (W) & 0 & -0.620 & -0.686 & -0.756 & -0.824 & -0.651 & -0.033 \\
\hline & D3 (W) & 0 & -1.154 & -1.244 & -1.339 & -1.431 & -1.192 & -0.038 \\
\hline & D4 (E) & 0 & -1.142 & -1.233 & -1.326 & -1.416 & -1.179 & 0.032 \\
\hline \multirow{13}{*}{$\begin{array}{l}\text { Strain Gauge } \\
\text { Rosettes }(\mu \varepsilon)\end{array}$} & $\begin{array}{l}\text { SR1-1A } \\
\text { (S/W) }\end{array}$ & $\mathrm{n} / \mathrm{a}$ & 0 & -14.21 & -29.55 & -43.94 & -1.14 & 14.64 \\
\hline & $\begin{array}{l}\text { SR1-1B } \\
\text { (S/W) }\end{array}$ & $\mathrm{n} / \mathrm{a}$ & 0 & -2.45 & -6.09 & -9.46 & -0.24 & 2.52 \\
\hline & $\begin{array}{l}\text { SR1-1C } \\
(\mathrm{S} / \mathrm{W})\end{array}$ & $\mathrm{n} / \mathrm{a}$ & 0 & 3.39 & 6.63 & 9.38 & 0.97 & -1.93 \\
\hline & $\begin{array}{l}\text { SR1-2A } \\
\text { (S/E) }\end{array}$ & $\mathrm{n} / \mathrm{a}$ & 0 & -20.35 & -42.04 & -62.96 & 0.04 & 18.79 \\
\hline & $\begin{array}{l}\text { SR1-2B } \\
\text { (S/E) }\end{array}$ & $\mathrm{n} / \mathrm{a}$ & 0 & -9.55 & -20.21 & -29.36 & 0.19 & 10.00 \\
\hline & $\begin{array}{l}\text { SR1-2C } \\
\text { (S/E) }\end{array}$ & $\mathrm{n} / \mathrm{a}$ & 0 & 4.89 & 8.63 & 13.44 & 0.94 & -2.63 \\
\hline & SR1-3A (W) & $\mathrm{n} / \mathrm{a}$ & 0 & -16.25 & -33.46 & -49.91 & -0.59 & 24.72 \\
\hline & SR1-3B (W) & $\mathrm{n} / \mathrm{a}$ & 0 & -6.14 & -12.94 & -19.58 & 0.85 & 7.84 \\
\hline & SR1-3C (W) & $\mathrm{n} / \mathrm{a}$ & 0 & 4.57 & 8.99 & 13.51 & 2.92 & -4.66 \\
\hline & SR1-4A (E) & $\mathrm{n} / \mathrm{a}$ & 0 & -14.64 & -30.29 & -46.25 & 0.24 & 20.80 \\
\hline & SR1-4B (E) & $\mathrm{n} / \mathrm{a}$ & 0 & -2.93 & -5.56 & -8.34 & 1.13 & 3.72 \\
\hline & SR1-4C (E) & $\mathrm{n} / \mathrm{a}$ & 0 & 3.19 & 6.89 & 10.32 & 3.49 & -0.77 \\
\hline & $\begin{array}{l}\text { SR2-1A } \\
(\mathrm{N} / \mathrm{W})\end{array}$ & $n / a$ & 0 & -13.23 & -27.39 & -41.76 & 6.89 & 19.05 \\
\hline
\end{tabular}




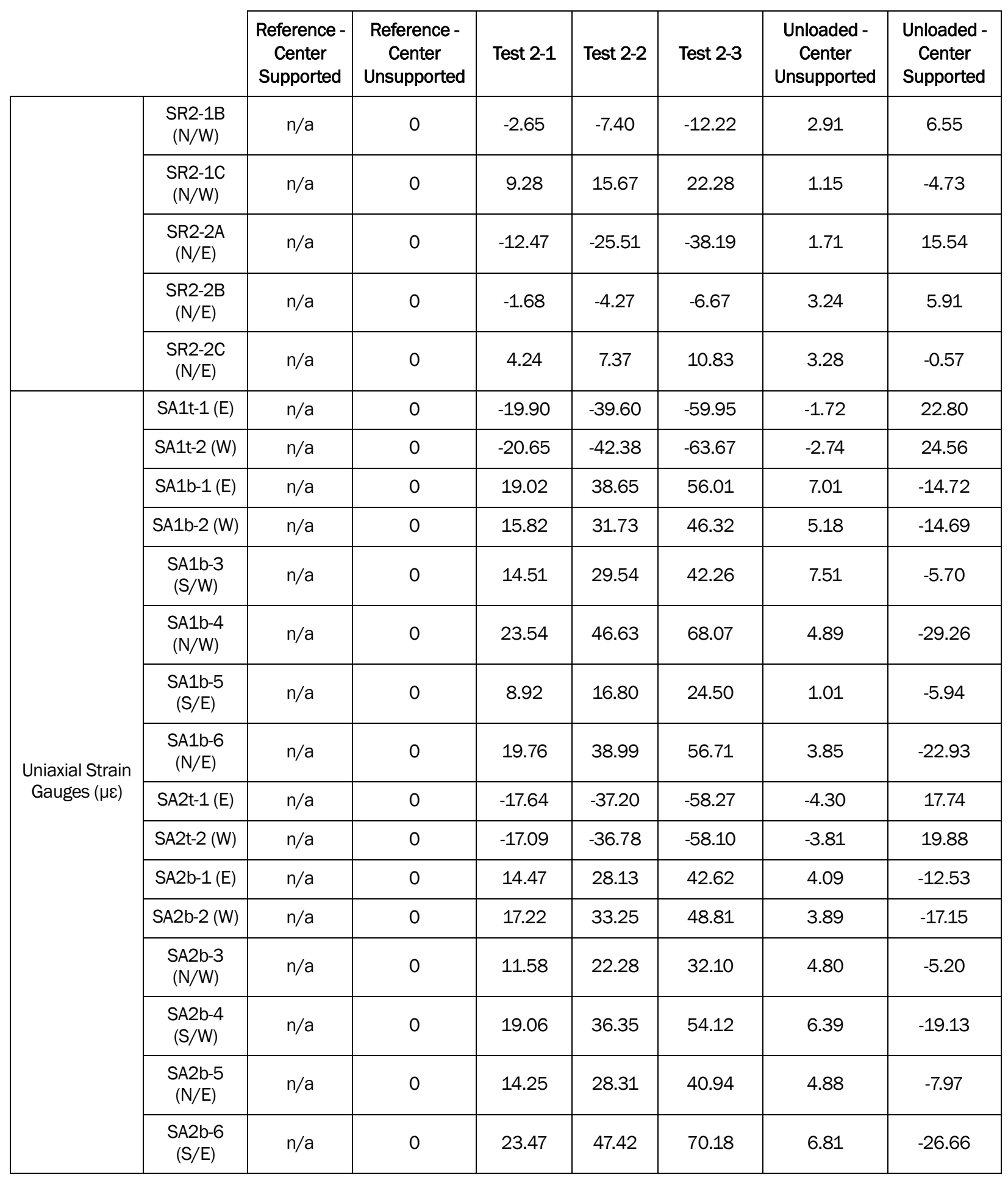




\section{Appendix: Bay Data 2018-03-02 and 2018-03-07}

The data collected during the single-bay and two-bay structural validation tests, executed on 2 March 2018 and 7 March 2018, respectively, are included in electronic (.csv) format as an appendix to this report. To view, please click on the following DOI:

http://dx.doi.org/10.21079/11681/37056 


\section{Unit Conversion Factors}

\begin{tabular}{|l|c|l|}
\hline Multiply & By & To Obtain \\
\hline degrees (angle) & 0.01745329 & radians \\
\hline feet & 0.3048 & meters \\
\hline foot-pounds force & 1.355818 & joules \\
\hline inches & 0.0254 & meters \\
\hline inch-pounds (force) & 0.1129848 & newton meters \\
\hline microinches & 0.0254 & micrometers \\
\hline microns & $1.0 \mathrm{E}-06$ & meters \\
\hline pounds (force) & 4.448222 & newtons \\
\hline pounds (mass) & 0.45359237 & kilograms \\
\hline square inches & $6.4516 \mathrm{E}-04$ & square meters \\
\hline tons (2,000 pounds, mass) & 907.1847 & kilograms \\
\hline
\end{tabular}




\title{
Acronyms and Abbreviations
}

\author{
BAP bridge adapter pallet \\ BSS Bridge Supplemental Set \\ ERDC US Army Engineer Research and Development Center \\ FEM finite element model \\ IRB Improved Ribbon Bridge \\ LVDT Linear Variable Differential Transformer
}




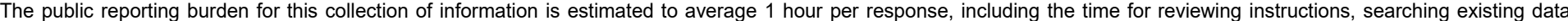

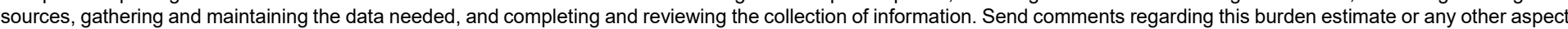

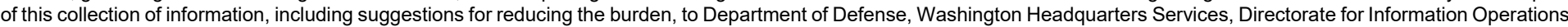

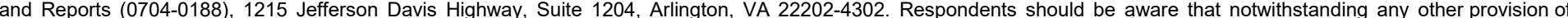
law, no person shall be subject to any penalty for failing to comply with a collection of information if it does not display a currently valid OMB control number. PLEASE DO NOT RETURN YOUR FORM TO THE ABOVE ADDRESS.

\begin{tabular}{l|l|l}
$\begin{array}{l}\text { 1. REPORT DATE } \\
\text { May } 2020\end{array}$ & $\begin{array}{l}\text { 2. REPORT TYPE } \\
\text { Final Report }\end{array}$ & 3. DATES COVERED (FrOm - To)
\end{tabular}

\section{TITLE AND SUBTITLE}

Improved Ribbon Bridge Structural Response Validation Testing

5a. CONTRACT NUMBER

5b. GRANT NUMBER

5c. PROGRAM ELEMENT NUMBER

622784

5d. PROJECT NUMBER

464569

5e. TASK NUMBER

16

5f. WORK UNIT NUMBER

8. PERFORMING ORGANIZATION REPORT

NUMBER

ERDC/GSL TR-20-22

US Army Engineer Resed
3909 Halls Ferry Road

Vicksburg, MS 39180-6199

9. SPONSORING/MONITORING AGENCY NAME(S) AND ADDRESS(ES)

Assistant Product Manager/Project Officer

Office of the Product Manager, Bridging

SFAE-CSS-FP-H, Bldg 230, Mail Stop \#401

6501 East 11 Mile Road

Warren, MI 48397-5000

12. DISTRIBUTION/AVAILABILITY STATEMENT

Approved for public release; distribution is unlimited.

13. SUPPLEMENTARY NOTES

Funding Account Code U4365732; AMSCO Code 622784T4000; MIPR 11326139

\section{ABSTRACT}

The Improved Ribbon Bridge (IRB) is a mobile, modular bridge system designed to provide wet-gap crossing capability to combat vehicles and trucks up to Military Load Capacity 96. The Bridge Supplemental Set (BSS) includes Bridge Erection Boats and an anchorage system to allow for the positioning and securing of the bridge in moving water. Designed to function as either a floating bridge or a raft, the IRB and BSS give military commanders multiple options with regards to the tactical river crossings.

The US Army Engineer Research and Development Center (ERDC) was contracted by Product Manager Bridging to provide a structural analysis via high-fidelity numerical modeling of various IRB spans and water flow rates. To this end, a finite element model (FEM) of the IRB was constructed using field measurements of IRB interior bays. To ensure accurate structural response characteristics of the FEM and to build confidence in the simulation results, a validation test series was devised to generate empirical data to correlate against. This report documents the IRB structural response validation testing conducted at ERDC in March 2018. The data contained in this report was used to validate the IRB structural FEM.

\section{SUBJECT TERMS}

Matting, Military bridges, Stream crossing, Military, Structural analysis (Engineering), Transportation, Military

\section{SECURITY CLASSIFICATION OF:}

\begin{tabular}{|l|l|l|}
\hline a. REPORT & b. ABSTRACT & c. THIS PAGE \\
Unclassified & Unclassified & Unclassified \\
\hline
\end{tabular}

17. LIMITATION OF ABSTRACT

SAR OF PAGES

43 19a. NAME OF RESPONSIBLE PERSON M. Wesley Trim

19b. TELEPHONE NUMBER (Include area code) 601-634-2701 